\title{
Review
}

\section{Smart E-Textile Systems: A Review for Healthcare Applications}

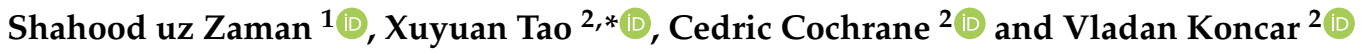 \\ 1 Department of Textile Engineering, School of Engineering and Technology, National Textile University, \\ Faisalabad 38000, Pakistan; shahood.zaman@ntu.edu.pk \\ 2 Génie et Matériaux Textiles Laboratory (GEMTEX), École Nationale Supérieure des Arts et Industries \\ Textiles (ENSAIT), 2 Allée Louis et Victor Champier, F-59100 Roubaix, France; \\ cedric.cochrane@ensait.fr (C.C.); vladan.koncar@ensait.fr (V.K.) \\ * Correspondence: xuyuan.tao@ensait.fr
}

check for updates

Citation: Zaman, S.u.; Tao, X.; Cochrane, C.; Koncar, V. Smart E-Textile Systems: A Review for Healthcare Applications. Electronics 2022, 11, 99. https://doi.org/ 10.3390/electronics11010099

Academic Editors: Paolo Visconti and Rashid Mehmood

Received: 24 November 2021 Accepted: 26 December 2021 Published: 29 December 2021

Publisher's Note: MDPI stays neutral with regard to jurisdictional claims in published maps and institutional affiliations.

Copyright: () 2021 by the authors Licensee MDPI, Basel, Switzerland. This article is an open access article distributed under the terms and conditions of the Creative Commons Attribution (CC BY) license (https:// creativecommons.org/licenses/by/ $4.0 /)$.

\begin{abstract}
E-textiles is a new hybrid field developed with the help of the integration of electronic components into our daily usage of textile products. These wearable e-textiles provide user-defined applications as well as normal textile clothing. The medical field is one of the major leading areas where these new hybrid products are being implemented, and relatively mature products can be observed in the laboratory as well as in commercial markets. These products are developed for continuous patient monitoring in large-scale hospital centers as well as for customized patient requirements. Meanwhile, these products are also being used for complex medical treatments and the replacement of conventional methods. This review manuscript contains a basic overview of e-textile systems, their components, applications, and usages in the field of medical innovations. E-textile systems, integrated into customized products for medical needs, are discussed with their proposed properties and limitations. Finally, some recommendations to enhance the e-textile system's integration into the medical field are argued.
\end{abstract}

Keywords: e-textile systems; medical e-textiles; healthcare e-textile systems; e-textile system reliability issues

\section{Introduction}

Modernization and digitalization are enhancing human life expectancy as we now have better resources to fight diseases and to detect them at their early stages. Novel techniques and user-defined products are attractive for people for the facilitation of their daily lives [1]. One classic example is the mobile and internet industry [2,3]. Currently, mobile phones are not only for communication via calling and messaging, but are also related to different daily life activities, including banking services, fitness, and health monitoring activities [4,5].

The concept of wearing cloth started with cultural evolution for the purpose of covering body parts. However, with time, textiles are now not only used for wearing purposes but have multiple value-added options [6-9]. In the current era of competition and the desire to attract more customers, the integration of multiple user-defined requirements into the conventional textile is often indispensable [10]. Initially, these concepts started in the medical industry, where the integrated sensors in undergarments were used to investigate different diseases. Nevertheless, they are not limited to this field only. At the moment, user-defined textile wearables are widely involved in numerous fields, including medical, sports, military, and different defense-related projects [11-13]. Modifications and additions have changed the approaches for using and developing wearable textiles. These modifications include the addition of passive or active sensors, actuators, etc., to detect the required changes and further to respond accordingly if required. The added components can be textile-based or non-textile-based. As such, the textile industry is now a combination subject of different industries in order to satisfy user-defined functionalities. Multipurpose 
and improved functional textiles may comprise one or several textiles or non-textile smart components that were integrated by different available techniques, such as weaving, knitting, embroidery, sewing, etc. [5]. Based on the requirements, these components can include sensors, actuators, antennas, processing units, energy storage, production and harvesting, and power transmitting devices [14,15]. These advanced wearable textiles are usually named smart textiles, wearable electronics, e-textiles, smart clothing, textronics, etc. $[8,16]$.

This manuscript is organized as follows. Firstly, we present the definition of smart textiles, especially for e-textile systems and e-medical/healthcare textile systems. Based on their usage, different healthcare e-textile categories are explained in detail with examples. In Section 3, we discuss the various healthcare products that are available or ready to be launched in the market along with their reliability and market acceptance issues. Section 4 explains the current research progress in e-textile healthcare systems. Finally, the existing challenges these healthcare systems are facing for their acceptance in the market are described, and a model approach to predict the washing reliability is also discussed.

\section{Smart Textiles}

The discovery of shape memory materials in the 1960s and intelligent polymeric gels in the 1970s have generally been accepted as the birth of smart materials [17]. However, the word smart material was first introduced in Japan in 1989. The first textile material in history that, in retrospect, was stated as a "smart textile" was silk yarn, which had a shape memory capacity. Although intelligent materials were first introduced in textiles in the late 1990s, the first textile electronic semiconductive components were acknowledged in the early 2000s [17].

Smart textiles can be defined as textiles that can sense and respond to stimuli from the external environment. They may be divided into two classes: passive and active smart textiles. Passive smart textiles can change their properties according to environmental stimulation. Shape memory materials, hydrophobic or hydrophilic textiles, etc., make up part of this category $[16,18,19]$. Active smart textiles generally contain sensors and actuators to connect the internal parameters to the transmitted message. They can detect different signals from the outer environment (temperature, light intensity, pollution, etc.), choose how to react, and finally act using various textile-based, flexible, or miniaturized actuators (textile displays, micro vibrating devices, LEDs, etc.). This "reaction" can be carried out locally, e.g., through electronic devices (textile electronics) embedded in the smart textile structures, or perhaps remotely, if the smart textile is wirelessly connected to external clouds containing the database [20].

\subsection{E-Textile System}

Unconditionally, it may be stated that all e-textiles can be considered as smart textiles; however, not all smart textiles need to be e-textiles. According to the definition from Stoppa et al. [21], Rambausek et al. [22] and Simegnaw et al. [23], an e-textile can be defined as "A textile structure (fiber, yarn, fabric or finished product) permanently integrated, sewn or attached, etc. with electrical and/or electronic functionality" [23]. Theoretically, the e-textile system is complex, with different inputs from the textile, wearable electronics, and computing to develop the hybrid system (Figure 1) [21,24-26].

E-textile systems are being widely used in different applications, and their usage depends on customers' requirements. Based on their applications, wearable e-textiles can be divided into five different categories, including healthcare, personal protection equipment (PPE), military, sports/leisure, and aesthetic/fashion categories (Figure 2) [2,27]. 


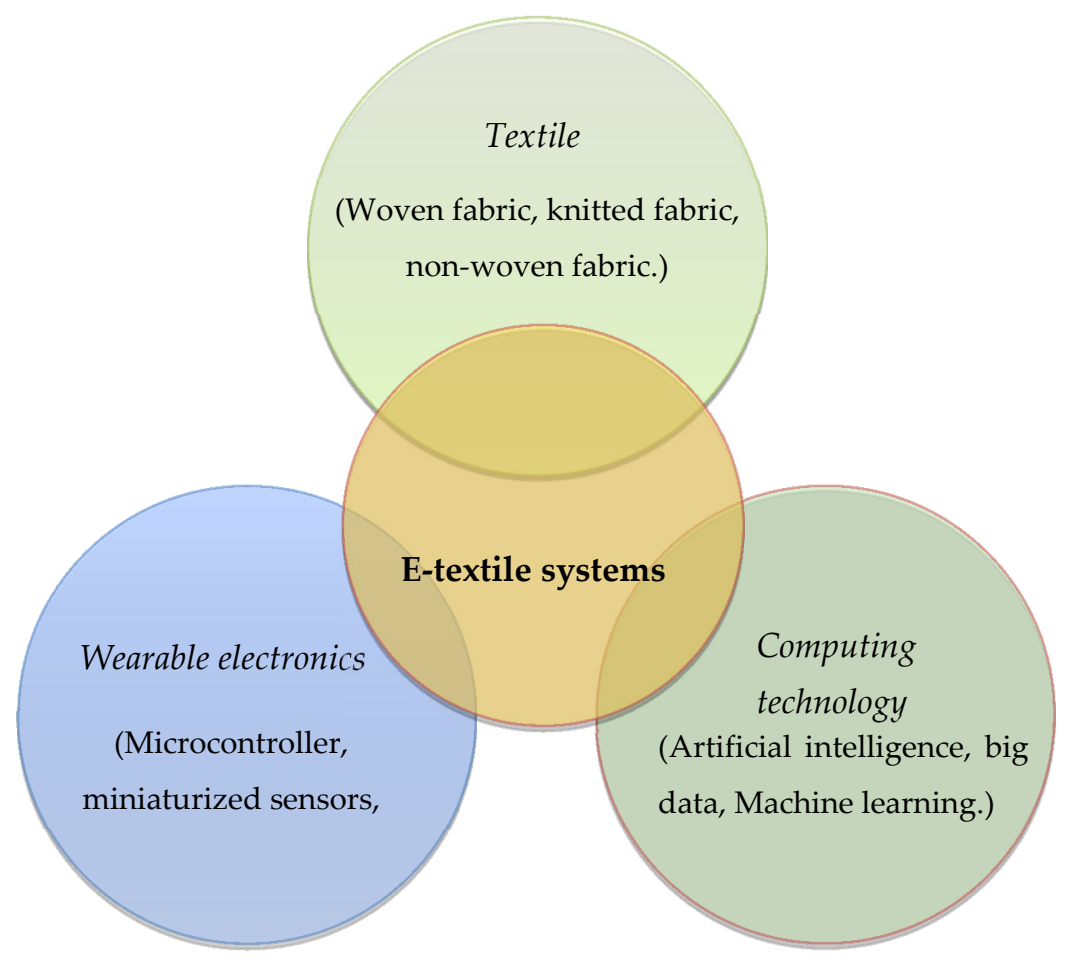

Figure 1. Wearable e-textile system.

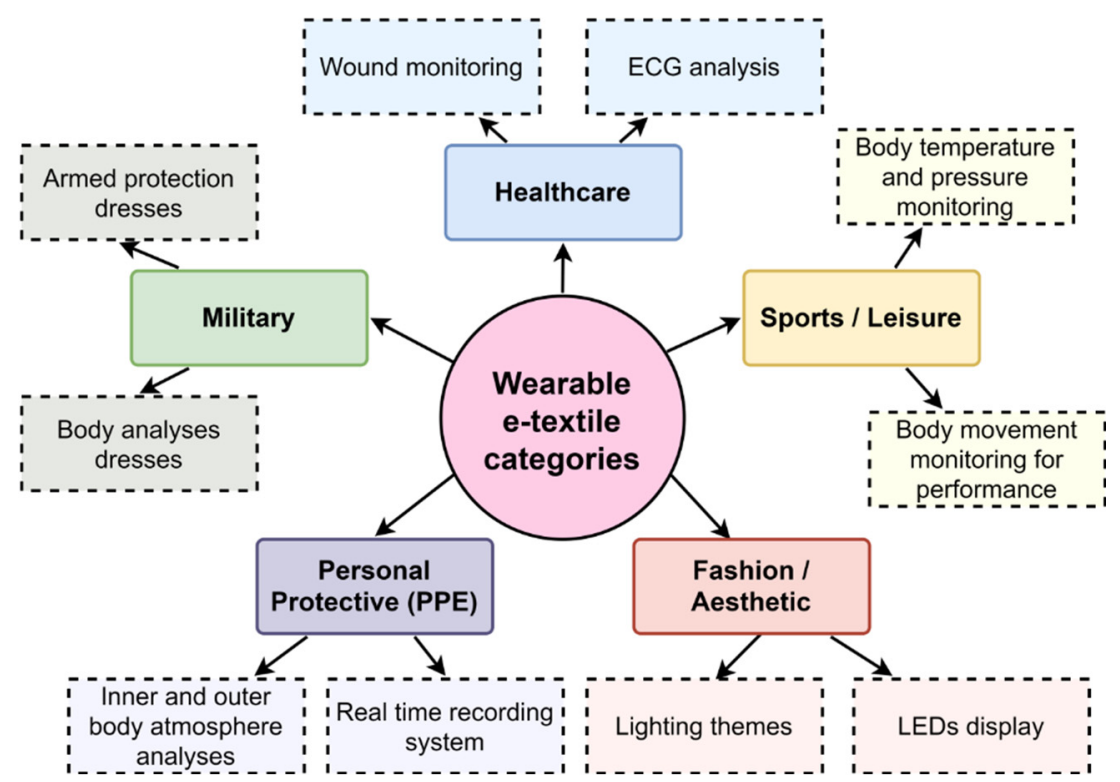

Figure 2. Wearable e-textile categories.

\subsection{E-Medical/Healthcare E-Textile Systems}

The smart textile market is flourishing day by day. Changes in human habits and the demand for user-defined facilities have increased the importance of e-textile systems in the normal textile market. Medical e-textiles were the first area where smart textile products were introduced $[28,29]$. Since then, the e-textile market has significantly improved for many applications in fitness monitoring, wireless communications, and defense purposes $[4,17,28,30]$.

The progressive development of the integration of electronic systems into textiles for e-textile systems and their applications has increased consumer awareness in this newly emerging field, which has witnessed a growing investment in e-textiles and their 
associated industries. As a result, this progress ultimately reduced the manufacturing cost and increased the ease of access to these emerging e-textile systems for customers [31,32]. However, it is too early to state that e-textile systems are comprehensively integrated into the "Internet of Things (IoT)" infrastructure. There is still room for improvements in terms of security, safety, and reliability to guarantee the IoT nodes for wearable e-textile products. As we progress in infrastructures and standardizations, we will see more products in the market and ultimately a neat growth rate [33,34].

A survey conducted by "MarketsAndMarkets" [35] claims that the global wearable healthcare market is projected to reach 46.6 billion US dollars in 2025 (Figure 3). In the wearable electronic market, still, a large portion is captured by wearable gadgets; however, smart clothing and e-textile medical systems are gaining rapid acceptance of customers. The adoption of mobile platforms, including AI and 5G, has also enhanced the acceptance of home healthcare devices of the customers $[33,34]$.

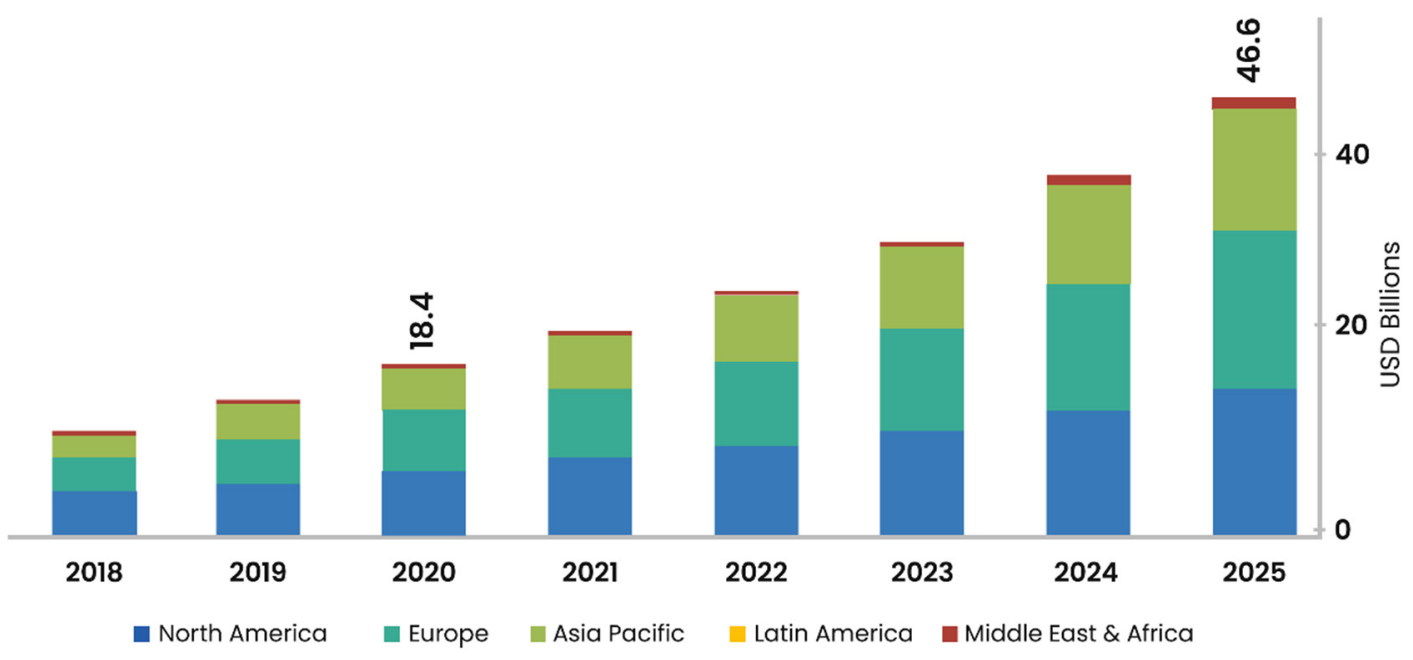

Figure 3. Healthcare wearable market prevision analyzed with the help of data from "MarketsAndMarkets" [35].

The medical field was one of the first fields where e-textile integration started initially. Nowadays, we can see many products related to the medical field that use "electronic structures." Wearable healthcare devices can typically be divided into two categories, including diagnostic and monitoring devices and therapeutic devices. These categories are explained in detail further into our discussion (Figure 4).

\subsubsection{Diagnostic and Monitoring Devices}

Wearable healthcare normally includes vital sign monitoring devices. This is the portion of the field where e-textile systems were initially attached; however, they are not limited to it now. One typical example is the use of ECG sensors in undergarments [8,36,37]. Textile-based flexible sensors can be integrated with undergarments, and hospitals can use these garments for real-time measurements in sensitive patients. This data can be forwarded to the central database in case any urgent action is required. Fiber optic sensors (FOSs), appropriate for monitoring biological parameters (e.g., respiratory and heartbeat monitoring), during magnetic resonance techniques and procedures, are also being used in the medical industry [5,38,39]. Figure 5 shows an example a of smart shirt designed for ECG measurement. In this typical example, six ECG sensors are attached to the shirt with the data collecting unit through conductive wires, that then transmit data to the external device with the help of installed Bluetooth antennas. A specially designed app is used to connect with this smart shirt, which is available in the market. These shirts have heart rate monitoring sensors developed using a special chip. An integrated battery is available that can be charged through a wireless charging system. Polyester and electronic-fiber 
material are used for the manufacturing of the shirts. Enhanced sensor quality enables a good quality signal with auto skin-detection. Thus, it is not necessary to power the shirt on or off, as the t-shirt will automatically detect when it is worn. These shirts are claimed to have better wash reliability at $30{ }^{\circ} \mathrm{C}$ with hand wash only. However, the sensor integration is performed in the form of chips; hence, we cannot say that they are textile-based wearable sensors. Despite this, the development of chip-based smart shirts have ultimately reduced the manufacturing cost as compared to other products and enhanced the washing reliability.

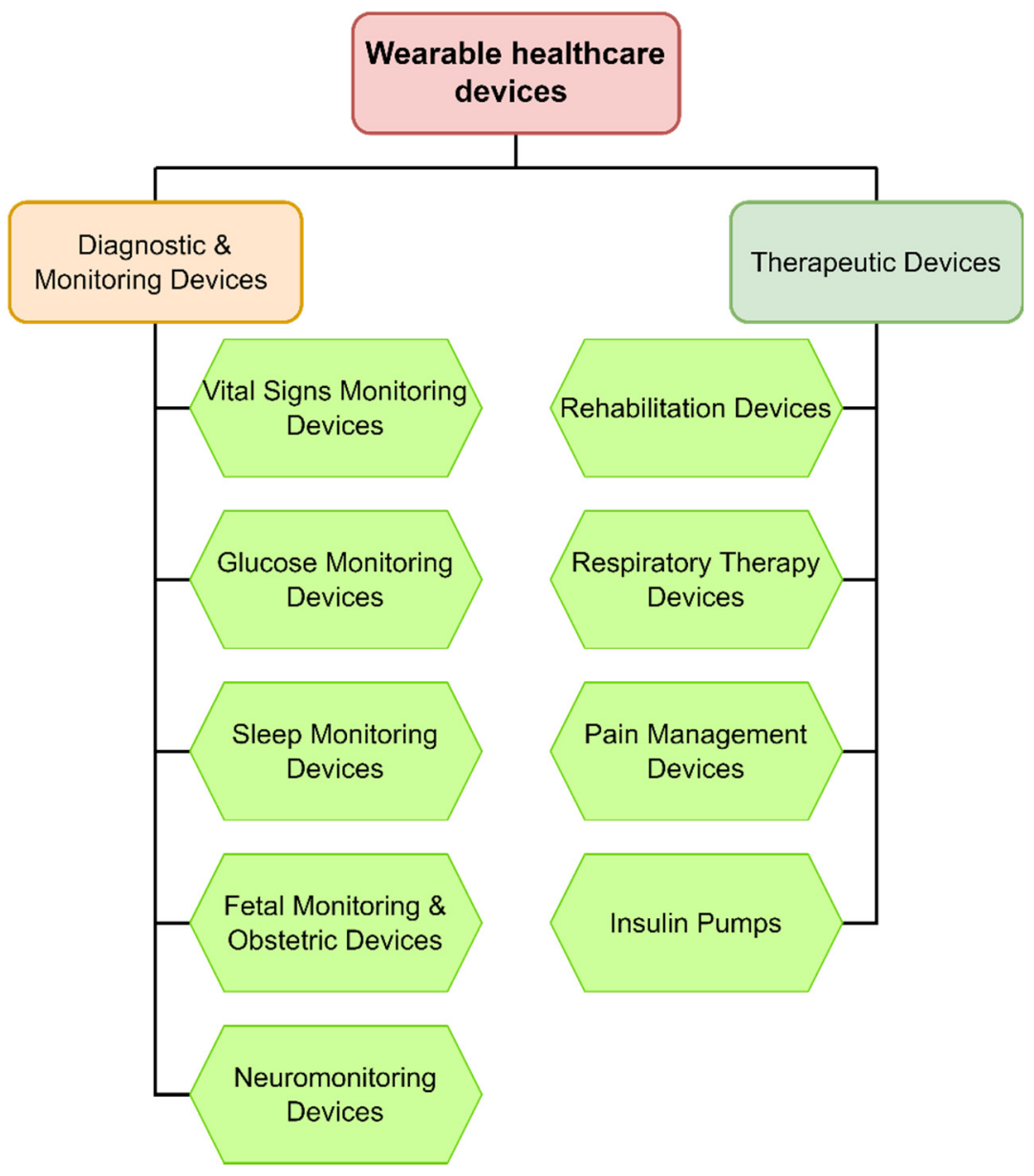

Figure 4. Healthcare e-textile devices.

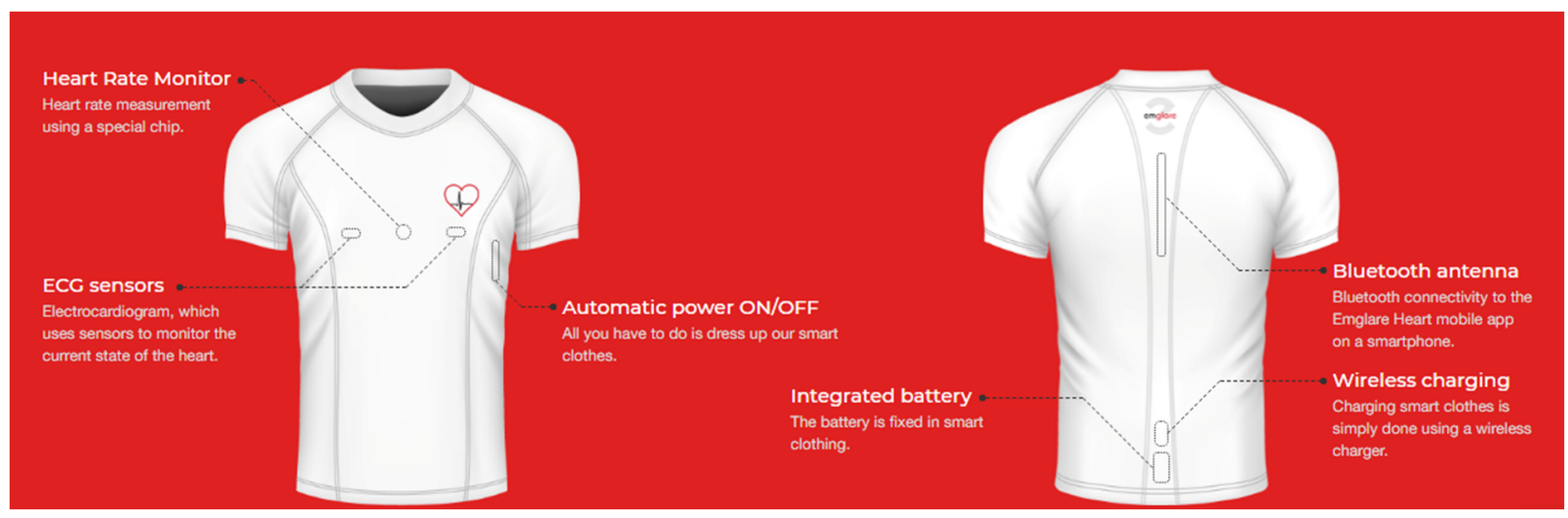

Figure 5. Smart ECG measuring shirt [40] (Reprinted with permission from Ref. [40]. Copyright 2021 emglare.com). 
The multiparameter tracker is another example that is often used nowadays. It was developed to detect various parameters, including ECG, temperature, blood pressure, heart rate, etc., under the same platform with the help of integrated sensors in the wearable smart textiles. The growing geriatric population and the increasing incidence of chronic disease has enhanced the investment in healthcare infrastructure [41]. The current COVID-19 pandemic has enhanced oximeter tracking, due to the customers' focus of self-monitoring. It is predicted that pulse oximeter market growth will be doubled in the next two years [42].

A typical example of a healthcare-designed smart $t$-shirt with multiple sensing options including body temperature, blood pressure, activity level, etc., is shown in Figure 6. In this prototype design, the blood pressure sensor is integrated into a smart shirt. Continuous cardiac, pulmonary, activity and sleep data analysis can be performed and recorded for a certain time by a three-axis accelerometer. This product is claimed to be machine washable, breathable, and lightweight. However, detachable components need to be removed before washing.

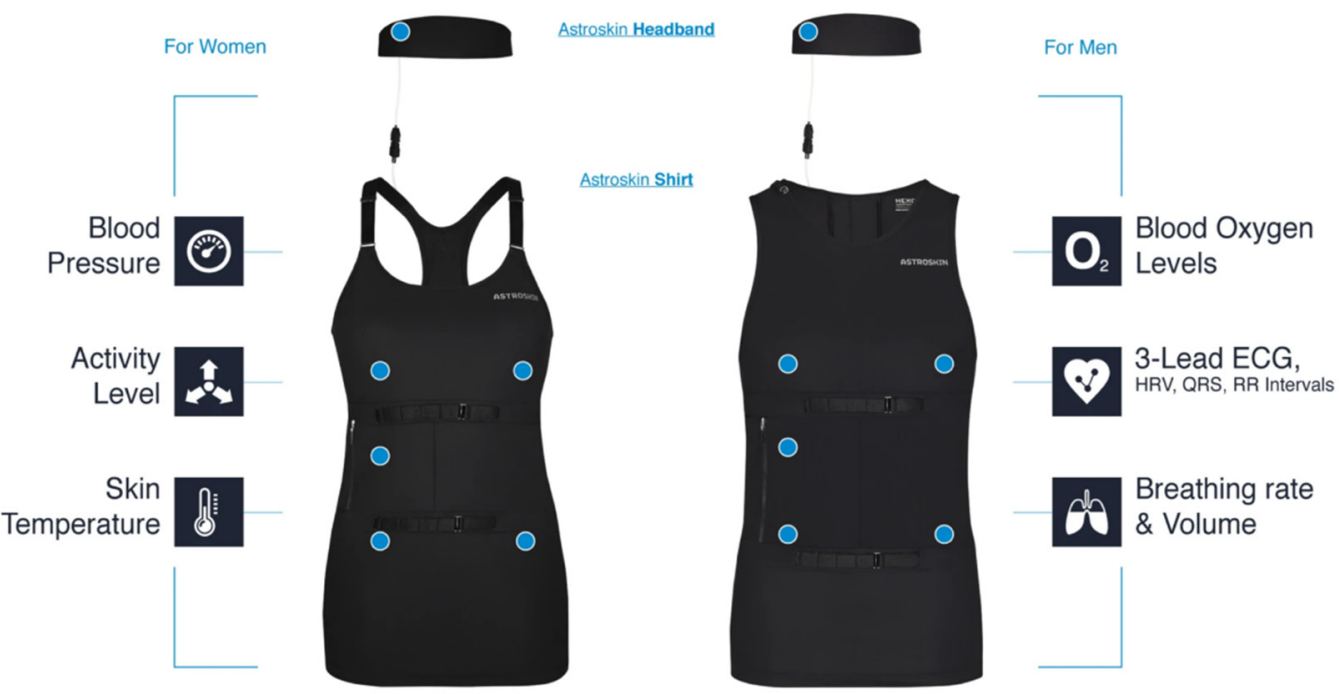

Figure 6. Healthcare e-textile system prototype design ("Astroskin" shirt by Carre Technologies Inc. (Hexoskin)) [43] (Reprinted with permission from Ref. [43]. Copyright 2021 Carre Technologies Inc.).

Another example is stretch sensors that can be used to monitor or detect body movements for some specific purpose or treatment. In Figure 7a, a prototype uses four wires as sensors for fingers. The sensors developed with four wires for each finger in the glove can detect hand movements that can be calculated with varying voltage output [21,44]. Piezoresistive fibers (carbon-coated fibers), elastic fibers, and regular polyester fibers were used to fabricate the yarn-based sensors using the double wrapping method. The control unit (32 MHz CPU board) is used to transmit the data used to make a hand gesture against various finger movements known as virtual reality.
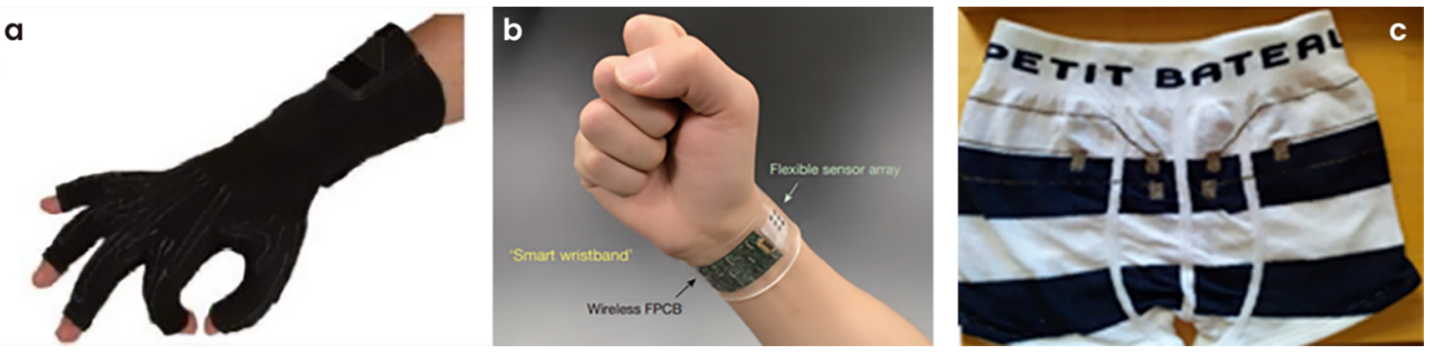

Figure 7. (a) DataGlove ${ }^{\mathrm{TM}}$ VRLOGIC with flex sensors [21]. (b) Photograph of a wearable FISA on a subject's wrist [45] (Reprinted with permission from Ref. [45]. Copyright 2021 Nature). (c) Trunk integrating leakage sensor embedded into children's underwear to detect urine leakage [46]. 
Figure $7 \mathrm{~b}$ shows a flexible integrated sensing array (FISA) [45] attached as a smart wrist band, which can be used for selective and simultaneous screening of metabolites and electrolytes in human perspiration. Skin temperature for indoor and outdoor activities can also be monitored. A flexible polyethylene terephthalate (FPET) substrate was used to fabricate the sensors. This flexible structure helped to achieve stable skin contact for the required duration. Various sensors, including lactate sensors, amperometric glucose sensors, potentiometric sensors, and enzymatic sensors were implanted with separate signal conditioning paths along with analog circuits and corresponding transduced signals. Various analyte solutions were used to monitor the performance of each sensor.

In another example (Figure 7c), children's undergarments were specially designed to detect urine leakage during sleeping, for children having enuresis problems. These sensors were attached to an alarm, with the help of wires, for quick communication of information to the parents. It works on real-time bio-impedance measurements. Leakage sensors detect the conductivity of urine liquid in the bladder, and signals are processed using electronic modules. Samples were prepared with three different types of conductive metallic yarns, made of silver or stainless steel. It was claimed that silver-based conductive yarns showed the best possible urine detection speed. However, electrical conductivity was compromised after multiple washing cycles at $60{ }^{\circ} \mathrm{C}$. This early detection can be attached to a mobile device with the help of Bluetooth data transfer possibilities [46].

\subsubsection{Therapeutic Devices}

Wearable e-textile systems have also been used in therapy treatments for the replacement of conventional methods. Pain management devices include neuromodulation devices, which are used for transcutaneous electrical nerve stimulation (TENS), and spinal cord stimulation (SCS) treatments. These pain management devices are also used for radiofrequency ablation and cryoablation treatments. Similarly, wearable textiles are also designed for the preparation of intrathecal infusion pumps and external infusion pumps. E-textile systems are also developed for facial and migraine pain treatments. On the other hand, cancer treatments have also experimented with wearable textile systems. The treatment of neuropathic pain is another example that is shifting towards e-textile system preparations.

Wearable e-textile systems are also being used in lung ventilation treatment and related cardiac functions $[47,48]$. Light-emitting wearable e-textile systems prepared with the help of optical fibers are being used for photodynamic therapy [49,50]. Similarly, chemical sensors integrated into wearable textiles are being used for metabolic disorder investigations [51]. Smart textiles are also being used for phototherapy. "NeoMedLight" [52] prepared a revolutionary "The BiliCocoon" nest and bag system. The nest system consists of a pad that allows wrapping and is used for kangaroo care and incubation. Figure 8 describes the photodynamic treatment with textile optical fibers. Here, flexible light-emitting woven structures were used for actinic keratoses treatments. The authors experimented with different types of structures, including woven-based, embroidery-based, panel-based containing micro-perforations, etc. After various experiments, they claimed that wovenbased structures gave the best results.

Wearable e-textile systems have also been developed for massage therapy, such as thermal therapy and ultrasound or infrared therapy equipment. Figure 9a [53] describes a textile-based vibrating kneepad for physiotherapy treatment. In most cases, knitted textile-based systems are preferred as they increase the pain threshold and reduce the muscular tension on the applied area. Similarly, in another example [54] (Figure 9b), a multilayer piezoresistive textile-based principle was developed for compression therapy treatments on human subjects. Alternate conductive and insulating textile layers were used in a vertical orientation. The rows of one layer were used to connect with the supply and the column of another layer to close the circuit. The overall device consists of 12 rows and six columns, with a total of 72 sensels in one device. 


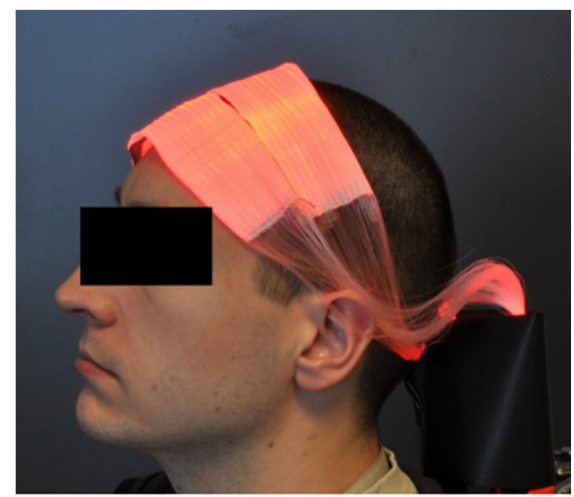

Figure 8. Photodynamic therapy treatment of actinic keratoses with light-emitting textiles [48] (Reprinted with permission from Ref. [48]. Copyright 2021 Elsevier).
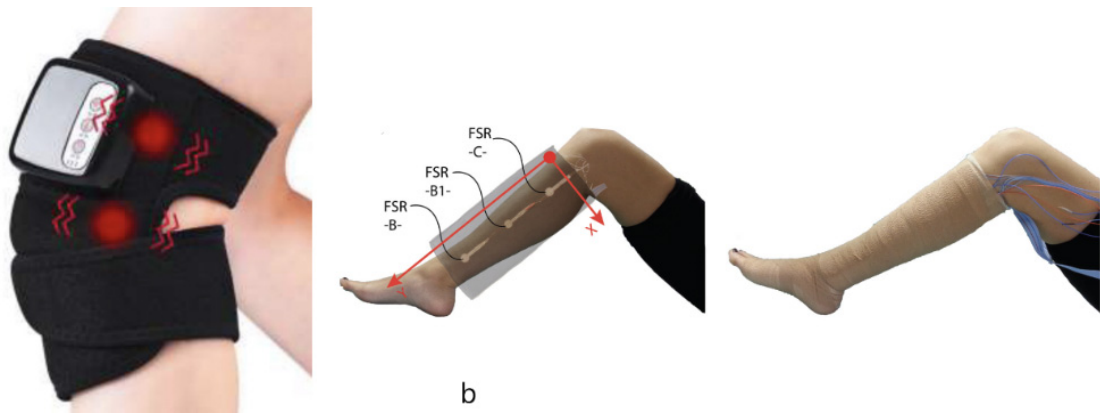

Figure 9. (a) Vibrating kneepad for physiotherapy [53]. (b) Textile sensor adjusted on the leg of a human volunteer (left) and complete bandage with the sensors attached inside, ready to be used by the public (right) [54] (Reprinted with permission from Ref. [54]. Copyright 2021 Sage Journals).

\section{Development of Healthcare E-Textiles for Commercial Purposes}

A great deal of progress has been observed in the healthcare system in recent years, and many lab-scale samples are available from research institutes. Some prototypes have been launched in the market for customer scale, and some are in the process of launching. Some examples are presented here.

The smart textile company "Kymira" [55] has developed a prototype of a cardiac monitoring $\mathrm{t}$-shirt used to detect the risk of heart attack in athletes. It transmits the heart rhythms to a mobile phone via Bluetooth; hence, an unusual rhythm that leads to sudden cardiac arrest can be detected. However, these products are still not available in the market for customers and their prices are not yet released. The Xiaomi Mijia [56] cardiogram t-shirt has integrated ECG sensors to monitor the patient's physical state. These shirts have a joint lighting system that can create an alert in the case of dangerous heart rate values by changing color according to the heart stroke intensity. The resulting cardiogram can also be downloaded via Bluetooth. These smart shirts are available on the market for only US $\$ 69$. However, their major limitation is the non-availability of machine washing.

"HealthWatch" [57] launched a 15-lead ECG-sensing shirt that allowed doctors and health workers to track heart conditions remotely. It is prepared with specially designed electrocardiogram sensors weaved into a synthetic or cotton t-shirt. These sensors can read vital signs and then transmit them to a monitoring device through Bluetooth. The manufacturer claims their product is suitable for the home machine washing process; however, the product is still in a demo state and independent reviews are not available in the market. AiQ Smart Clothing [58] prepared different variants, including vests, t-shirts, and sports bras, with five types of electrode structures suitable for various applications. They can be used for heart monitoring by fitness enthusiasts, as heart monitoring compression vests for marathons and cycling, for elderly care units as 1-3 lead ECG monitoring vests physically 
or remotely, and for cardiac rehabilitation and fitness. One advantage is their recommendation for machine washing, which enhances their positive image with customers. However, these products are only at the prototype stage and are still not available for sale.

The Emglare smart $t$-shirt [40] is another example of a smart $t$-shirt with integrated ECG and heart rate monitoring sensors attached to a mobile application for data recording and transfer to medical experts. Their main limitation is minimal washing instructions, which increases doubts about their lifespan. However, they are currently only in the pre-order state at the price of US \$249. Another example is Sensoria fitness products [59]. Their smart sock is prepared with high-tech fabrics instrumented with textile sensors. Sensoria care microelectronics are attached externally with a snap button. These socks are attached with Bluetooth smart cool, which counts footsteps, calories burnt, altitude, and tracks distance. It can also detect injury-prone running patterns to reduce harm. The Sensoria fitness smart t-shirt (Figure 10) provides consistent heart rate reading without any additional strap wearing. The information can be stored in mobile applications through Bluetooth data transfer. It also provides antimicrobial and moisture evaporation properties. However, the electronic sensors must be removed before washing. These fitness products are more suitable for athletes focusing on their fitness at a good price range of US \$129.
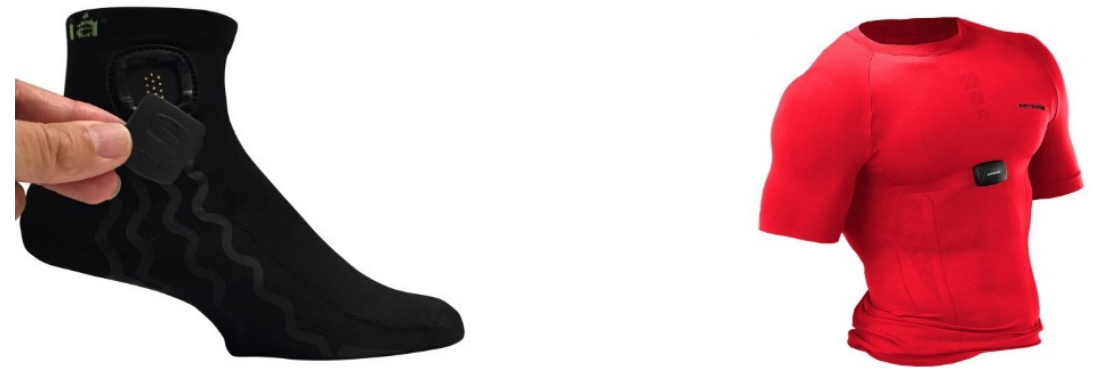

Figure 10. Sensoria fitness products [59] (Reprinted with permission from Ref. [59]. Copyright 2021 Sensoriafitness).

Table 1 shows these examples for proper understanding.

Table 1. Different e-textile products with availability and price.

\begin{tabular}{|c|c|c|c|c|}
\hline Brand & Max. Temp. & Instructions & Machine Wash & $\begin{array}{c}\text { Product Availability } \\
\text { (Price) }\end{array}$ \\
\hline Kymira heart monitoring t-shirt & $30{ }^{\circ} \mathrm{C}$ & Do not tumble dry & Yes & Not available \\
\hline Xiaomi Mijia smart t-shirt & $30{ }^{\circ} \mathrm{C}$ & Gentle wash & No & $\begin{array}{l}\text { Available } \\
\text { (US \$69) }\end{array}$ \\
\hline Sensoria fitness smart t-shirt & & $\begin{array}{l}\text { Remove sensors before } \\
\text { washing }\end{array}$ & Yes & $\begin{array}{l}\text { Available } \\
\text { (US \$129) }\end{array}$ \\
\hline Emglare smart shirt & $30^{\circ} \mathrm{C}$ & Minimal washing & Yes & $\begin{array}{l}\text { Pre-order } \\
\text { (US \$249) }\end{array}$ \\
\hline AiQ Sports Bra & & Machine washable & Yes & Not available \\
\hline HealthWatch ECG t-shirt & & Home machine washable & Yes & Demo \\
\hline CuteCircuit smart shirt & & Washable & No & $\begin{array}{l}\text { Pre-order } \\
(£ 550)\end{array}$ \\
\hline
\end{tabular}

\section{Research Progress in Healthcare E-Textile System Development}

\subsection{Development of Diagnostic and Monitoring Devices}

The uses of textile-based sensors in daily life are increasing based on their different applications, including physical and biochemical sensing $[41,60]$. One common example is flexible/stretchable stress-strain sensors. The impact of stress on textile fabric or the amount of recovery against it can be detected and recorded using these sensors. Conductivecoated knitted fabrics are commonly available on the market [61]. Graphene-coated fabrics 
and carbon nanotube (CNT)-based fabrics are also available on the market. Pressure sensors are another form of textile-based sensor. They can be resistive pressure sensors or capacitive pressure sensors [62]. Temperature sensors are also being used widely in the smart textile industry. These sensors can be integrated into the system or may be applied independently for some specific applications. These sensing mechanisms may be piezoelectric, piezoresistive, or capacitive sensing [63]. They are used for in-patient or routine tracking for different medical-based sensing.

Real-time tracking of electrocardiogram (ECG) data can be used to alert the patient before a fatal mishap, such as a stroke or a heart attack; thus, life can be saved. Textile sensors can be fabricated/encapsulated in undergarments at different positions [64,65]. These electrodes can record sensitive pulse movements and ECG signals. The generated data can further be used to detect and indicate different medical diseases [39,66]. Meghrazi et al. [67] prepared textile electrodes and placed them at different waist positions for ECG signal detections. Signals were recorded at different body positions, including sitting, standing, jogging, etc. Multi-channel knitted sensors were prepared with the help of conductive carbon and silver yarn. The authors claimed to achieve good results in both the standing and sitting positions [68]. Arquilla et al. [69] (Figure 11) developed textile-based ECG skin electrodes by sewing silver-plated conductive yarns on normal fabrics in a zigzag pattern. ECG data acquisition was carried out by three lead positioning systems and compared with normal gel electrodes. Eight different subjects were tested for these sensors, and their heart rate and R-R interval (from PQR ECG graph) were recorded. For comfort analysis, a Wilcoxon signed-rank test was carried out. Wang et al. [70] reported textile-based flexible sensors for monitoring ECG and breathing. Weft-knitted sensors were embedded at different positions in undergarments. Conductive silver-platted nylon filament yarn was used for sensor preparations. However, washing reliability for these types of undergarments still needs to be discussed.

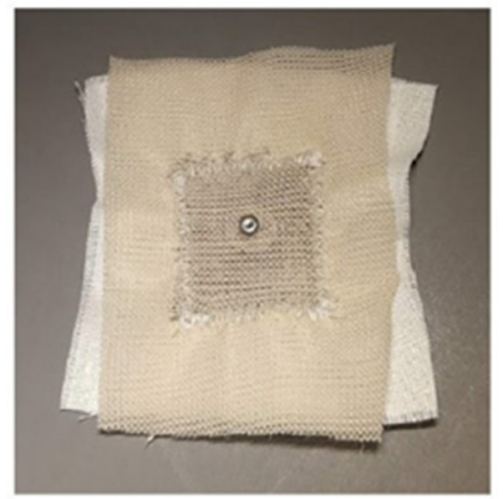

Figure 11. Textile-based ECG sensors [69].

Shathi et al. [71] worked on graphene-based washable textile electrodes using the pad-dry-cure method. Graphene solution was padded with the help of solution baths and then dried at $60{ }^{\circ} \mathrm{C}$ before curing was achieved at $90{ }^{\circ} \mathrm{C}$. To verify their samples, the authors performed different tests for the electrodes, including tensile strength, water contact angle, and colorfastness to rubbing. ECG responses at different body positions were monitored and claimed to be acceptable. Bystrickt et al. [36] investigated the ECG textile sensors and compared the knitted and embroidered-based sensors in terms of performance. SilveR.STAT ${ }^{\circledR}$ and X-STATIC monofilament continuous fibers were used for the preparation of these sensors. These threads have a continuous polyamide filament core and a thin pure silver layer on them. In both the knitted and embroidered cases, the authors found problems in the dry (without gel) measurement, such as movement of electrodes due to muscular activity and false peak generation due to the lack of moisture on the electrodes. However, these electrodes were sufficient to detect the P wave, QRS complex, and for heart monitoring. Saleh et al. [72] produced textile-based flexible ECG sensors with graphene 
oxide, and a reduction process was carried out to obtain reduced graphene oxide cotton electrodes (rGOC). They experimented with various dipping times ranging from $1 \mathrm{~min}$ to $30 \mathrm{~min}$ to obtain the best possible conductivity. Moreover, different electrode shapes, including rectangular, circular, and square, were also investigated. These samples were used for ECG signal detection. Fu et al. [73] discussed different types of ECG electrodes and their performance. They explained the importance and convenience of dry textile electrodes for long-term monitoring. These electrodes can be adapted to different shapes easily and according to body position.

Nigusse et al. [74] (Figure 12) developed washable silver printed textile electrodes that can be used for long-term ECG monitoring. The authors claimed that these electrodes had a surface resistance of $1.64 \Omega$ /sq. They stated that the signal quality of these electrodes was parallel to the standard $\mathrm{Ag} / \mathrm{AgCl}$ electrodes, even after 10 washing cycles. Kim et al. [75] prepared textile-based electrodes for electrocardiogram measurements. They investigated the impact of electrode size and textile pressure on signal quality. Similarly, chemical sensors integrated into the textile substrate can be used to investigate metabolic disorders. Shi et al. [76] and Grancaric et al. [51] worked on glucose-sensing electrodes integrated into the textile substrate along with $\mathrm{pH}$, sodium, and calcium-sensing electrodes. These electrodes justified a comprehensive datasheet about sweating.
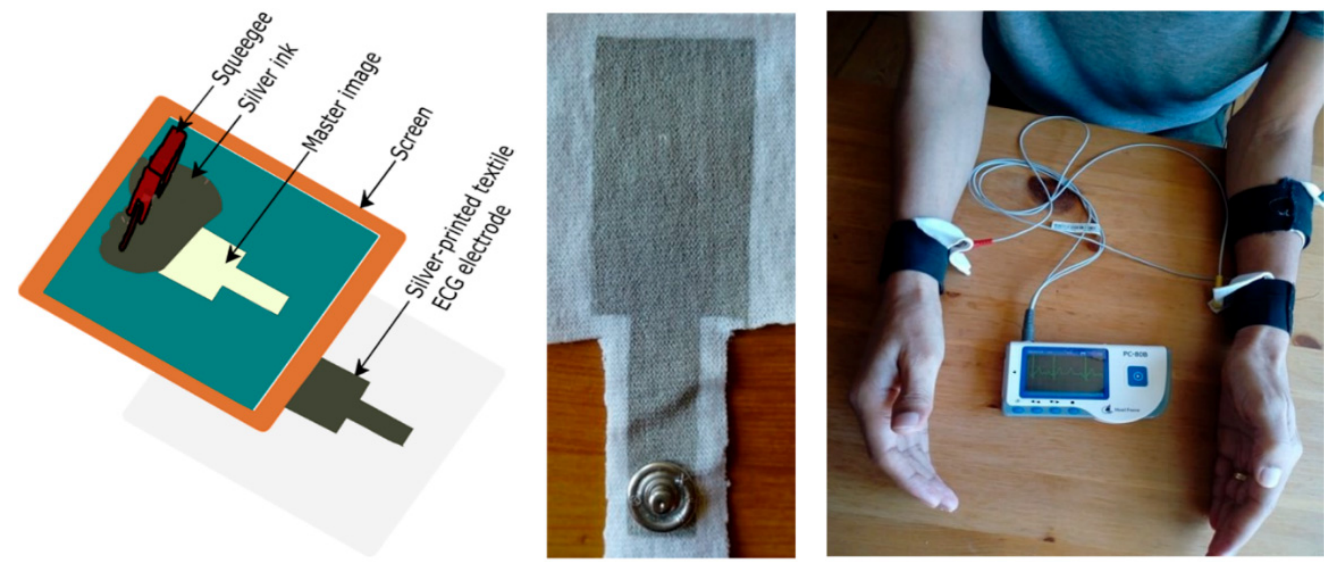

Figure 12. (Left to right) Block diagram for screen printing process; front view of the developed electrode; component placement setup for ECG measurement [74].

Pressure sensors can be used to investigate sleep analysis. These sensors can be integrated into a sleeping mattress, and body movement during sleep can be recorded. In addition, these sensors can be attached to wrist bands, and heart rate data can be collected precisely based on muscular pressure sensing. This data can further be used to predict sleep quality and other diseases. These sensors can also be integrated into sportswear. They can be installed into the inner footwear sole. Foot posture during jogging can be monitored and used to improve performance. Similarly, real-time heart monitoring of players can be useful to investigate their performances in different sports activities.

Shathi et al. [71] prepared pressure sensors to investigate minor pulse rate changes by applying them to the wrist. They used the pad-dry-cure method for the preparation of graphene-coated flexible sensors. A layer-by-layer technique was used to deposit PEDOT:PSS (Poly(3,4-ethylenedioxythiophene) polystyrene sulfonate) on graphene oxide. They calculated the pulse rate at different positions, including sitting, walking, and running. The post-treatment effects of ethylene glycol (EG) and dimethyl sulfoxide (DMSO) on these sensors were also investigated. The authors claimed that post-treatments reduced the sheet resistivity to $130 \pm 0.5 \Omega$, which is sufficient to detect the sensitive body responses. The results showed that graphene-coated sensors may be adopted for better and relatively quick responses in various healthcare and bio-medical devices. Atakan et al. [77] produced a smart chest band. Accelerometers and gyroscope sensors were integrated into this chest band with a normal sewing method. The bands were then used for mobility 
and fall detection during sports activities. They used elastomeric nylon yarn for the band preparation. Available IMU (accelerometers and gyroscope sensors) were sewn in these bands. Cao et al. [78] experimented with electronic textile sensors with screen printing. They used carbon nanotubes (CNT) for screen printing ink and prepared the three layers of pressure sensors with the help of a hot press machine. They used different fabric types, including silk, nylon, flax, cotton, wool, and leather. These sensors were then fixed in gloves, and finger movements were analyzed based on the pressure change in sensors. Sliz et al. [79] prepared roll-to-roll printed flexible electrodes for multi-purpose e-textile applications. Qureshi et al. [80] developed flexible strain sensors using Ny-6 (polyamide 6.6) yarn with silver nanoparticles plated on it. The silver nanoparticles were deposited on the yarn using an electroless plating process.

Zhao et al. [81] prepared multifunctional strain sensors. PET (polyethylene terephthalate)based Ag sensors were used for static and dynamic strain mapping. Different human body motions and pressure and strain distribution are recognized in various body positions. This low-cost sensor array may be helpful for next-generation human-machine interfaces. Zhang et al. [82] prepared silver/silver chloride woven electrodes with uniform micro-convex shapes for different health monitoring applications. These electrodes enhanced the impedance reliability with the skin for long-term monitoring. The monitoring performance was analyzed with a different set of $\mathrm{Ag} / \mathrm{AgCl}$ electrodes in terms of the skin-electrode interface impedance and electrode resistance.

Jin et al. [83] prepared a four-channel electromyogram (EMG) monitoring garment using the printing process. They developed electrically and mechanically stable wiring structures by monitoring ink permeation in textiles using butyl carbitol acetate. The authors claimed sheet resistance as low as $0.06 \Omega$ /sq with an increase of 70 times after $450 \%$ strain. This stretchable and mechanically stable conductive ink can be used on different textile substrates for multiple e-textile applications, especially health monitoring sensors. Logothetis et al. [84] reported silver-plated e-textile electrodes for bioelectrical impedance analysis. The electrodes contained three different materials, including silver plated thread, PES (polyester) thread, and substrate. Cotton and polyester substrates with different weaving techniques were used. The e-textiles were tested under different ambient conditions, and a change in resistance was calculated.

Likewise, motion sensors can be integrated into the textile substrate. Motion and strain sensing gloves are currently available on the market. These gloves can precisely detect the motion of arms and fingers [85]. LED displays can further be attached to these motion sensors; thus, different motions can be highlighted with different colors on the textiles. One good example of their potential application is for traffic control officers. They can use their arm positions to blink different colors on their jackets, and these signals can be seen from a distance. These sensors can also be used in hospitals to detect patient movement either through their hospital gowns or through a centralized display in nurse restrooms. Kim et al. [15] produced single-layer pressure sensors with conductive wool yarn. Gloves with encapsulated sensors at different finger positions were prepared and changes in resistance with finger movements was recorded. Figure 13 describes the pressure sensor movement for various fingers in the process of holding a water glass.

Afroj et al. [86] investigated graphene-based electronic textiles that can be used in ultra-flexible supercapacitor and skin-mounted strain sensors. Graphene was encapsulated on textiles with a scalable pad-dry-cure method, and the claimed surface resistance was $11.9 \Omega$ /sq. Danova et al. [87] worked on piezoresistive elastic sensors for human breath analysis. They prepared a commercially available t-shirt integrated with piezoresistive elastic sensors prepared with a purified multiwall carbon nanotube (MWCNTs) network synthesized with the help of a chemical vapor deposition method and encapsulated by elastic silicon. This composite structure was filtered through the membrane and then welded directly on the t-shirt. It was further encapsulated by a thin silicone layer. Tang et al. [88] developed textile electrodes for the replacement of ECG acquisition through capacitive 
electrodes. They proposed a controlled electrode humidification system that could better perform in different ambient conditions.
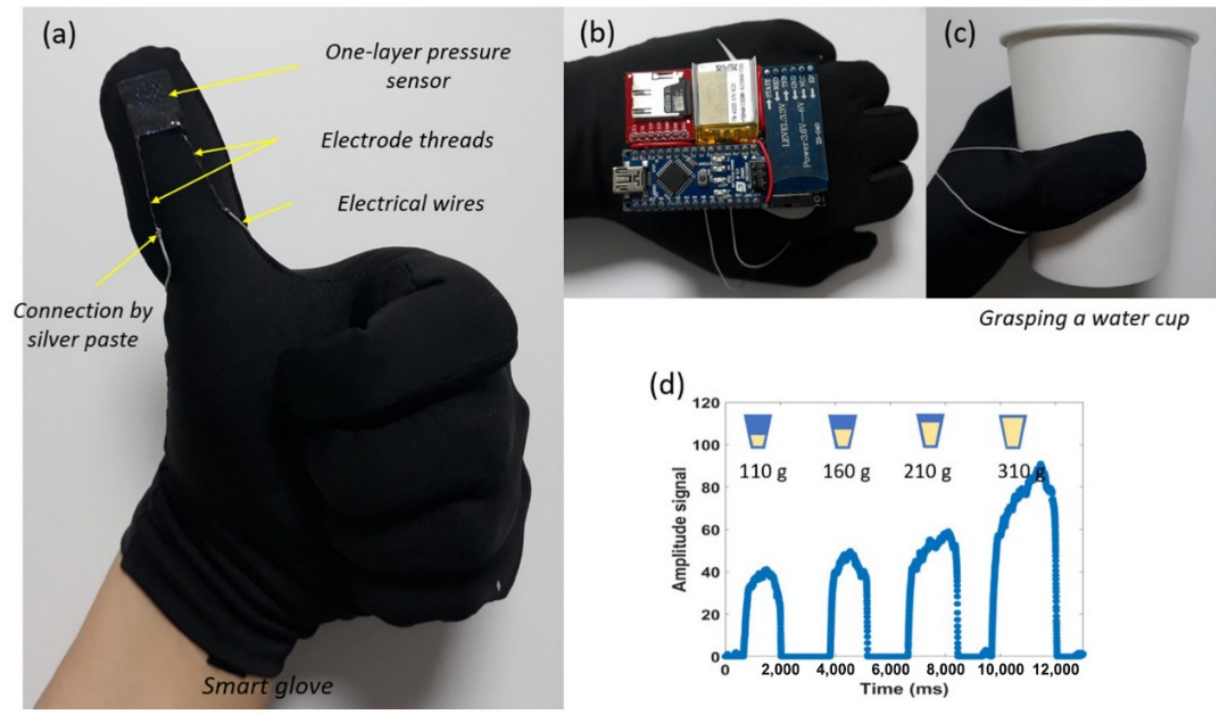

Figure 13. (a) Pressure sensor installed in glove. (b) Sensor diagram, with (c) holding a water cup of various weight. (d) Signal amplitude against time in ms [15].

An overall comparison of different laboratory work and prototypes prepared for diagnostic and monitoring devices is presented in Table 2.

Table 2. Detailed comparison of current progress in diagnostic and monitoring Devices.

\begin{tabular}{|c|c|c|c|}
\hline Authors & Targeted Area & Manufacturing Technique & Conductive Material Used \\
\hline Meghrazi et al. [67] & ECG at waist position & Multi-channel knitted textile & Carbon/Silver \\
\hline Arquilla et al. [69] & ECG at chest mount & Sewn textile & Silver coated threads \\
\hline Wang et al. [70] & ECG in undergarments & Weft-knitted & $\begin{array}{l}\text { Silver-plated nylon filament } \\
\text { yarn }\end{array}$ \\
\hline Shathi et al. [71] & ECG at various positions & Pad-dry-cure method & Graphene-based electrodes \\
\hline Bystrickt et al. [36] & ECG in tops and the straps & Knitted and embroidered & silveR.STAT ${ }^{\circledR}$ and X-STATIC \\
\hline Saleh et al. [72] & ECG & $\begin{array}{l}\text { The cotton textile reduction } \\
\text { process }\end{array}$ & $\begin{array}{l}\text { Reduced graphene oxide cotton } \\
\text { electrodes }\end{array}$ \\
\hline Nigusse et al. [74] & ECG & $\begin{array}{l}\text { Knitted cotton and polyester } \\
\text { fabric }\end{array}$ & Screen-printed electrodes \\
\hline Gaubert et al. [46] & Urine leakage sensors & $\begin{array}{c}\text { Seamlessly integrated into textile } \\
\text { underwear }\end{array}$ & $\begin{array}{l}\text { Stainless steel and silver-plated } \\
\text { conductive yarns. }\end{array}$ \\
\hline Shathi et al. [71] & Pulse rate sensor & Pad-dry-cure method & Graphene coated textile \\
\hline Atakan et al. [77] & $\begin{array}{l}\text { Accelerometers and } \\
\text { gyroscope sensors }\end{array}$ & Knitted band & $\begin{array}{l}\text { Elastomeric nylon yarn and } \\
\text { IMU sensor }\end{array}$ \\
\hline Cao et al. [78] & $\begin{array}{l}\text { Finger movement analysis } \\
\text { (strain) }\end{array}$ & Screen printing & Carbon nanotubes (CNT) \\
\hline Zhao et al. [81] & Strain sensor & Weaved & PET-based Ag sensors \\
\hline Kim et al. [15] & Pressure sensor & Sewn & Conductive wool yarn \\
\hline Danova et al. [87] & Piezoresistive elastic sensors & Welded directly on the $\mathrm{t}$-shirt & $\begin{array}{l}\text { Multiwall carbon nanotubes } \\
\text { (MWCNTs) }\end{array}$ \\
\hline
\end{tabular}




\subsection{Therapeutic Devices}

In modern medical treatments, different techniques are practiced for disease treatment, and these advancements have impacted a great deal in modern healthcare systems. Optical fiber-based smart textiles are being used for treatments for different diseases. Wavelength selection is a major factor for light therapy treatments, as the change in light wavelength modifies the light penetration into human skin tissues [89,90]. Figure 14 highlights the light penetration phenomenon in the human body with the increase in wavelength.

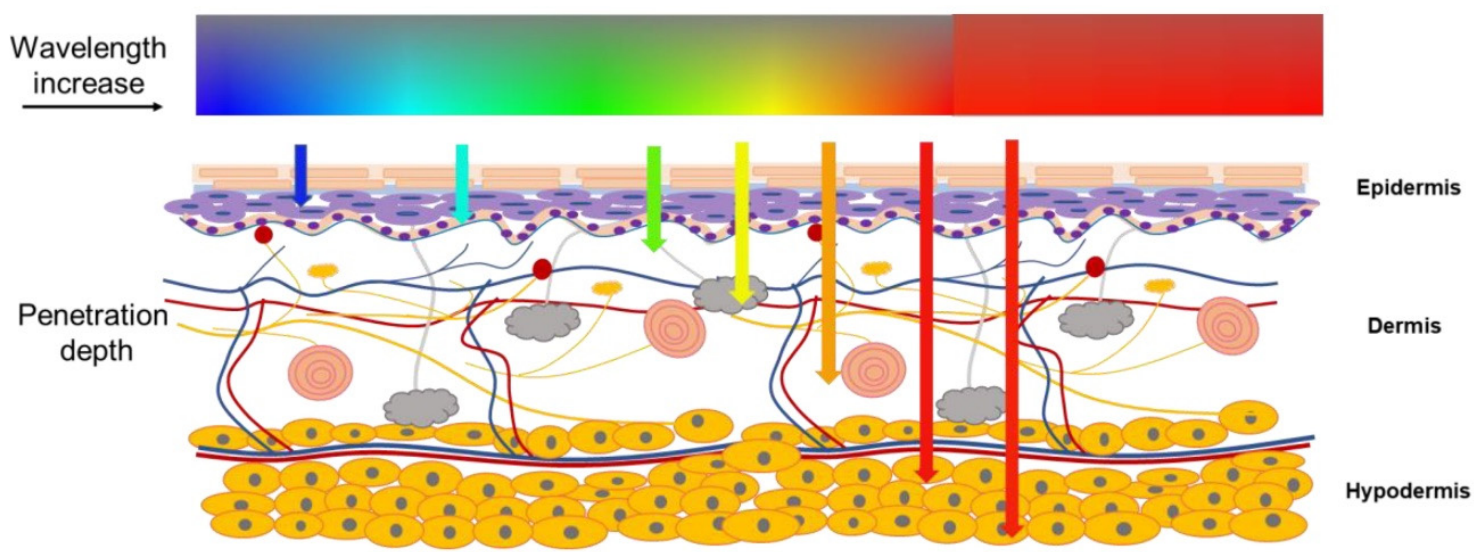

Figure 14. Varying depths of light penetration in human skin tissue [89].

Shin et al. [91] developed a woven device for three-dimensional low wavelength therapy (600-950 nm). They claimed a stable operating temperature and optical power density for continuous treatment up to $10 \mathrm{~h}$ without any damage in contact with human skin. POFs (polymer optical fibers) of $250 \mathrm{~nm}$ were used for these experiments. The developed prototype example is presented in Figure 15.

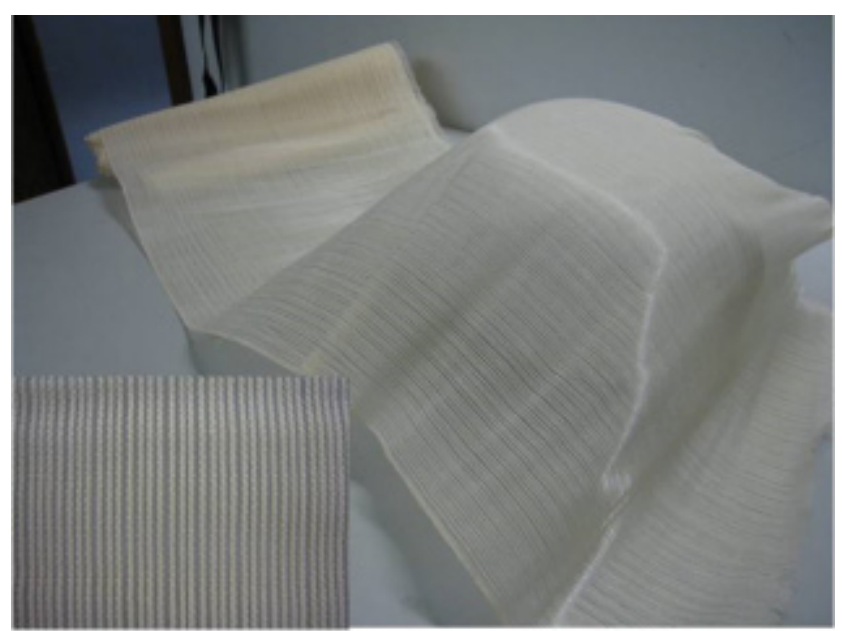

Figure 15. Woven fabric produced by cotton yarn and POF (polymer optical fibers) [91] (Reprinted with permission from Ref. [91]. Copyright 2021 Biomedical Optics Express).

Cinquino et al. [90] presented the detailed working principle and applications of light-emitting textiles, especially in therapeutic devices. Light therapy can be used for pain relief treatments, tissue repair, complex disease treatments, etc. The fabrication of portable light-emitting fabrics has also enhanced the comfort level of patients. Additionally, light loss during the therapy treatment is also reduced, as the fabrics are flexible and are shaped to skin curves to enhance the contact surface with the skin.

Mordon et al. [92] worked on light-emitting fabrics and their usage in vivo and vitro for photodynamic treatments (PDT). They claimed uniform light-emission for the light- 
emitting fabric (LEF) devices designed for dermatology treatments. For in vitro (CELL-LEF) applications, these devices produced illumination of 96-well culture plates. Figure 16 describes the light therapy treatment example at different positions. The device has three light-emitting flexible fabrics, each illuminating with a $635 \mathrm{~nm}$ laser at a low fluence rate for one complete minute. A total irradiation time of $2.5 \mathrm{~h}$ helped to deliver a light dose of $37 \mathrm{~J} / \mathrm{CM}^{2}$ to any part of the treated area.
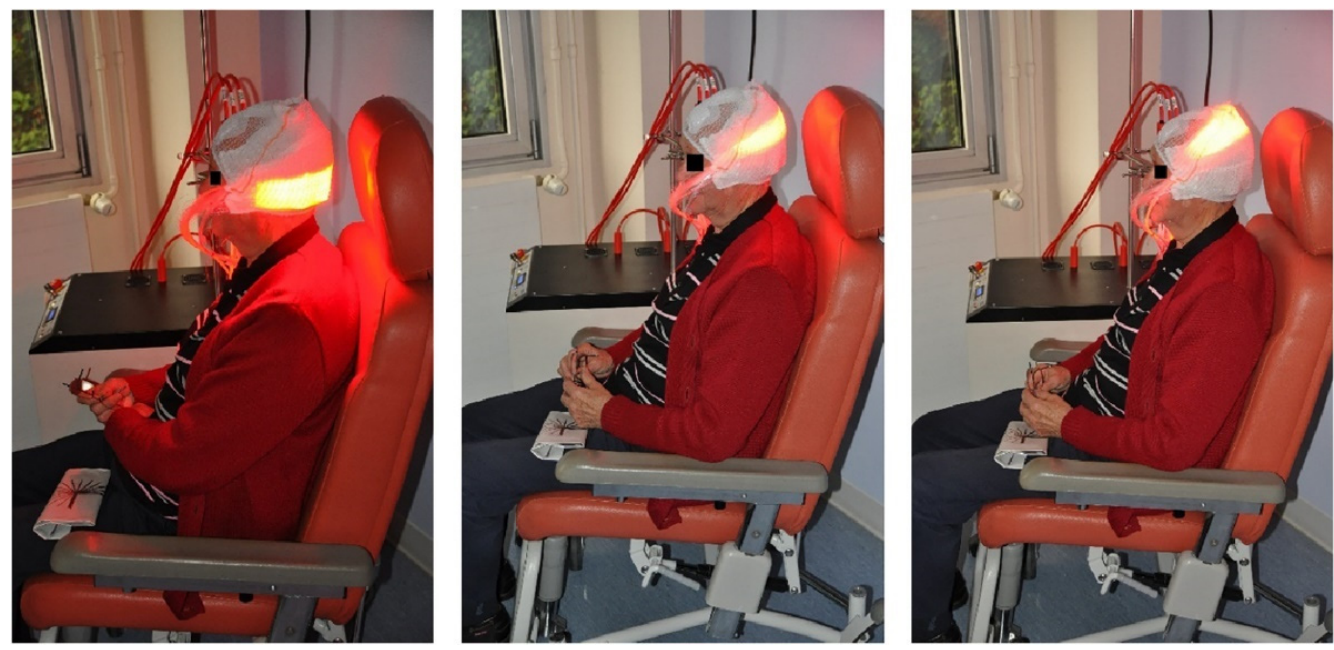

Figure 16. Each light-emitting fabric (LEF) sequentially emits $635 \mathrm{~nm}$ red light for $1 \mathrm{~min}$ resulting in a fractionated irradiation (1 min light, 2 min dark) [92] (Reprinted with permission from Ref. [92]. Copyright 2021 Translational Biophotonics).

Rymarczyk et al. [47] proposed a system that records lung ventilation and cardiac function through a wearable garment. Different algorithms and image analyzing techniques were used to observe the changes during measurements. These models were used to investigate the heart, lungs, and skin. The main idea was to enhance the tomographic data collection speed with reliable algorithms. Wang et al. [93] prepared nanomesh organic electrochemical transistors for medical and fitness sensing applications. They preferred the spray coating techniques to deposit the PEDOT:PSS on the mesh structure. The nanomesh structure was successfully fabricated to achieve the active electronic elements. The structures were developed as the active on-skin electrodes for electrophysiological signal acquiring and were compatible with existing electrophysiology recording equipment. The authors claimed to achieve simultaneous local amplifications of ECG signals on human skin with a high signal-to-noise ratio of $25.89 \mathrm{~dB}$.

Shahariar et al. [94] researched printed electronic material by the direct-write printing process on different types of substrates for healthcare applications. They used three different types of laminates, including polyethylene terephthalate (PET) nonwoven textiles, thermoplastic polyurethane (TPU), and nylon-PET nonwoven textiles. The durability of these types of sensors was directly related to the ink-fiber microstructure attachment and penetration into the surface.

Quandt et al. [95] claimed the development of high-quality light-emitting textiles that could be used for neonatal jaundice treatments (Figure 17). The developed textile showed only $4 \%$ light intensity variation; thus, it can be claimed to be homogenous. These photonic textiles can easily be adopted for the required power density and spectral irradiance; hence, these devices can easily be used as continuous treatments at home. 


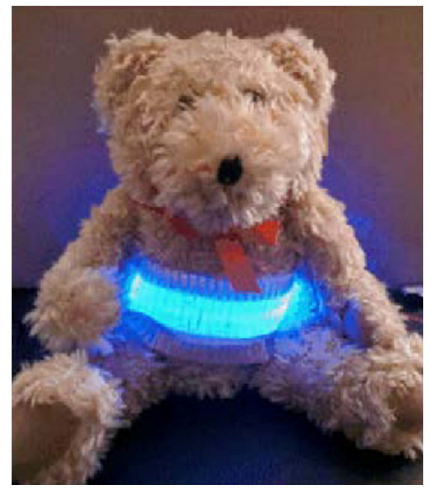

Figure 17. The fabric is wrapped around a teddy with 120 POF illuminated [95] (Reprinted with permission from Ref. [95]. Copyright 2021 Biomedical Optics Express).

Table 3 shortlists the current development and research outcomes for textile-based therapeutic devices used in the healthcare system.

Table 3. Detailed comparison of current progress in therapeutic devices.

\begin{tabular}{cccc}
\hline Authors & Targeted Area & Manufacturing Technique & Conductive Material Used \\
\hline Shin et al. [91] & Light therapy & $\begin{array}{c}\text { Used in weft insertion during } \\
\text { weaving }\end{array}$ & $\begin{array}{c}\text { (PMMA) fiber core and a } \\
\text { fluorinated PMMA } \\
\text { derivative cladding }\end{array}$ \\
\hline Cinquino et al. [90] & Light therapy & $\begin{array}{c}\text { LEDs/OLEDs coupled with POF } \\
\text { (polymer optical fibers) }\end{array}$ & POF (polymer optical fibers) \\
\hline Mordon et al. [92] & $\begin{array}{c}\text { Photodynamic treatments } \\
\text { (dermatology treatments) }\end{array}$ & $\begin{array}{c}\text { Optical fiber is woven by } \\
\text { conventional methods }\end{array}$ & Optical fibers \\
\hline Shahariar et al. [94] & Wearable textile heaters & Direct-write printing & PET non-woven, TPU, nylon PET \\
non-woven
\end{tabular}

\section{Challenges for Healthcare E-Textiles}

Washability and reliability are the major issues facing wearable textiles nowadays [96-98]. Various prototypes, as discussed in Section 3 (smart shirts, socks, ECG sensing shirts, etc.), are available on the market, and they are quote successful in meeting the user requirements. However, these products are lacking in terms of washability and wash reliability. Wash reliability depends on the proper functioning of the complete e-textile system after the predefined number of wash cycles. Different standards are available for textile wash protocols; however, they cannot work for e-textile products. Special precautions should be adopted for electronic textile washability [99,100].

Unfortunately, there is not much work focused on the reliability issues of healthcare wearable e-textile systems, and for this reason we cannot see many products available on the market. Some researchers have performed the washing reliability experiments for their products; however, reliability issues are still a major hurdle for these products.

Kim et al. [75] used a mini wash machine to wash textile sensors for up to 50 wash cycles. Gaubert et al. [46] prepared urine leakage sensors encapsulated in underwear and washed these sensors in a household machine for 20 wash cycles. Cao et al. [78] developed electronic textile electrodes with screen printing and claimed washability after immersing them in water for $15 \mathrm{~h}$. Afroj et al. [86] investigated graphene-based electronic textiles and washed them for up to 10 household wash cycles using the AATCC 105 standards, and claimed no change after these washes. Shahariar et al. [94] prepared printed electronic material by the direct-write printing process on different types of substrates. These samples were washed for 25 wash cycles according to the AATCC 61-2a. Hwang et al. [101] claimed 
machine washable, highly conductive, silk-coated yarn for electronic textile applications in healthcare. They washed the prototypes for 10 wash cycles; however, no further details were explained. Salavagione et al. [102] investigated conductive smart textiles with graphenebased coating on the textile and washed them for 10 wash cycles; however, no further explanation was provided again. The effects of bleaching agents on the morphology of silver coating and loss of conductivity after certain wash cycles were discussed. These yarns were investigated in household machines according to AATCC 135 standards. A total of 30 wash cycles, with a 60 min process for each cycle with a speed of $900 \mathrm{rpm}$ and a temperature of $30{ }^{\circ} \mathrm{C}$, were used for this experiment. Sliz et al. [79] checked rollto-roll printed flexible electrodes for multi-purpose healthcare e-textile applications. The mechanical behavior and wash properties of these electrodes were investigated. They were washed at $40{ }^{\circ} \mathrm{C}$ for $63 \mathrm{~min}$ and up to 10 wash cycles at $1000 \mathrm{rpm}$ in a normal household machine. Saleh et al. [72] produced textile-based flexible ECG sensors with graphene oxide, and a reduction process was carried out to obtain reduced graphene oxide cotton electrodes (rGOC). The conductivity of these electrodes was above $70 \%$ of the original value after five wash cycles. Again, no further details about the wash process were provided. Liang et al. [103] developed different types of textile stretch sensors. A washability test was performed for these samples in a front load washing machine for three washing cycles, according to ISO 6330:2012 test protocols.

In our previous experiments $[8,97,104]$, different-textile components, such as conductive tracks, flexible textile ECG sensors, flexible PCBs, and textile antennas, were investigated for washing reliability. As these e-textile systems, when purchased by customers, will undergo a normal washing process, their washing reliability should be investigated using the normal household washing process.

These e-textile system components were washed with the help of a household washing machine to investigate the provoked damages. Alternate available textile testing methods were also studied to correlate the washing damages. Accelerometer analysis, was performed by putting an accelerometer in the washing machine to investigate the e-textile system behavior during the washing process. All these experimental analyses explained two different types of behavior, in terms of mechanical stresses, for the fabric undergoing the washing process. The first type is the falling movement of the samples in the low-speed rotation due to gravity. Usually, the pilling box test has a rotational speed ranging from 30 RPM to 60 RPM, which is close to the washing drum speed that was 38 RPM. As for the second type of behavior, the fabric was stuck on the drum wall under a pressure force due to centrifugal force, and it rubbed against the drum wall. The Martindale abrasion test may simulate these mechanical stresses. This test is performed by applying a certain known pressure on the fabric in one direction and under-pressure sliding movements in other directions. This phenomenon can give a close simulation of high-speed rotation under rotational force.

In the example of conductive tracks prepared by silver-coated polyamide yarn (Figure 18), 1000 abrasion cycles produced damage almost equivalent to that provoked by eight Silk washing cycles or five Express washing cycles. The change of resistance from original resistance $\mathrm{R}^{\prime} / \mathrm{R}$ was measured against different mechanical actions and washing actions. These test results may be used to predict the number of washes that e-textile prototypes can withstand. The same experiments were also performed with the pilling box test, where 1000 pilling cycles produced damage to the transmission lines equivalent to four Silk washing cycles or three Express washing cycles.

These two available test procedures (pilling box and Martindale) can simulate and predict similar damage in the washing process without using the washing machine. Figure 19 demonstrates the proposed idea to predict the washing damages caused by specific stresses. As a result, the actual washing process can be replaced by mechanical tests, and the reliability of e-textile components can be tested at each step during the manufacturing process of the e-textile systems. More detailed information about the washing test results can be found in $[8,94]$. 


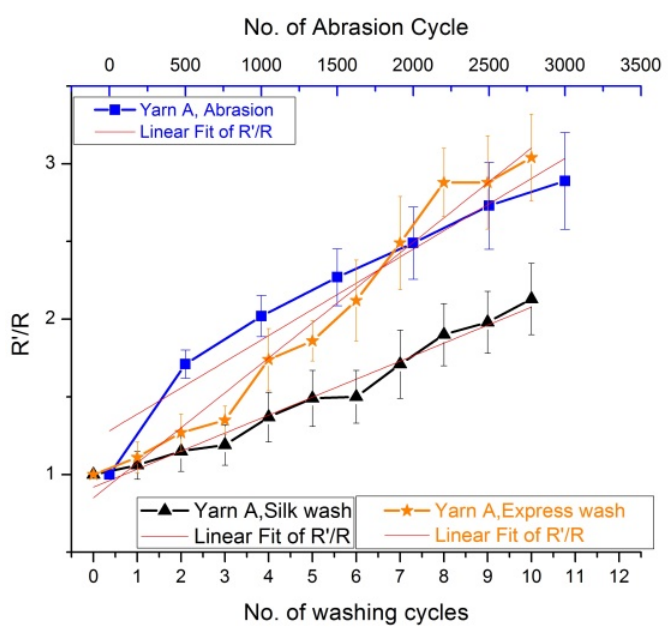

(a)

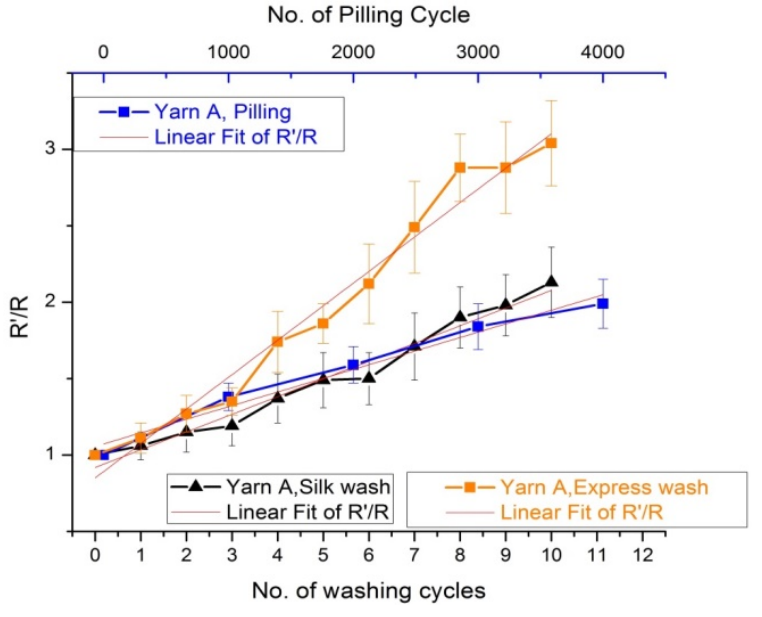

(b)

Figure 18. (a) $R^{\prime} / R$ values for yarns with a three-line stitch after 4000 pilling cycles and 10 washing cycles. (b) R'/R values for yarns with a three-line stitch after 4000 pilling cycles and 10 washing cycles. $R^{\prime} / R$ is the ratio of change in resistance from original; $R^{\prime}$ represents the changed resistance value and $R$ represents the initial resistance value [97] (Reprinted with permission from Ref. [97]. Copyright 2021 Fibres and polymers).

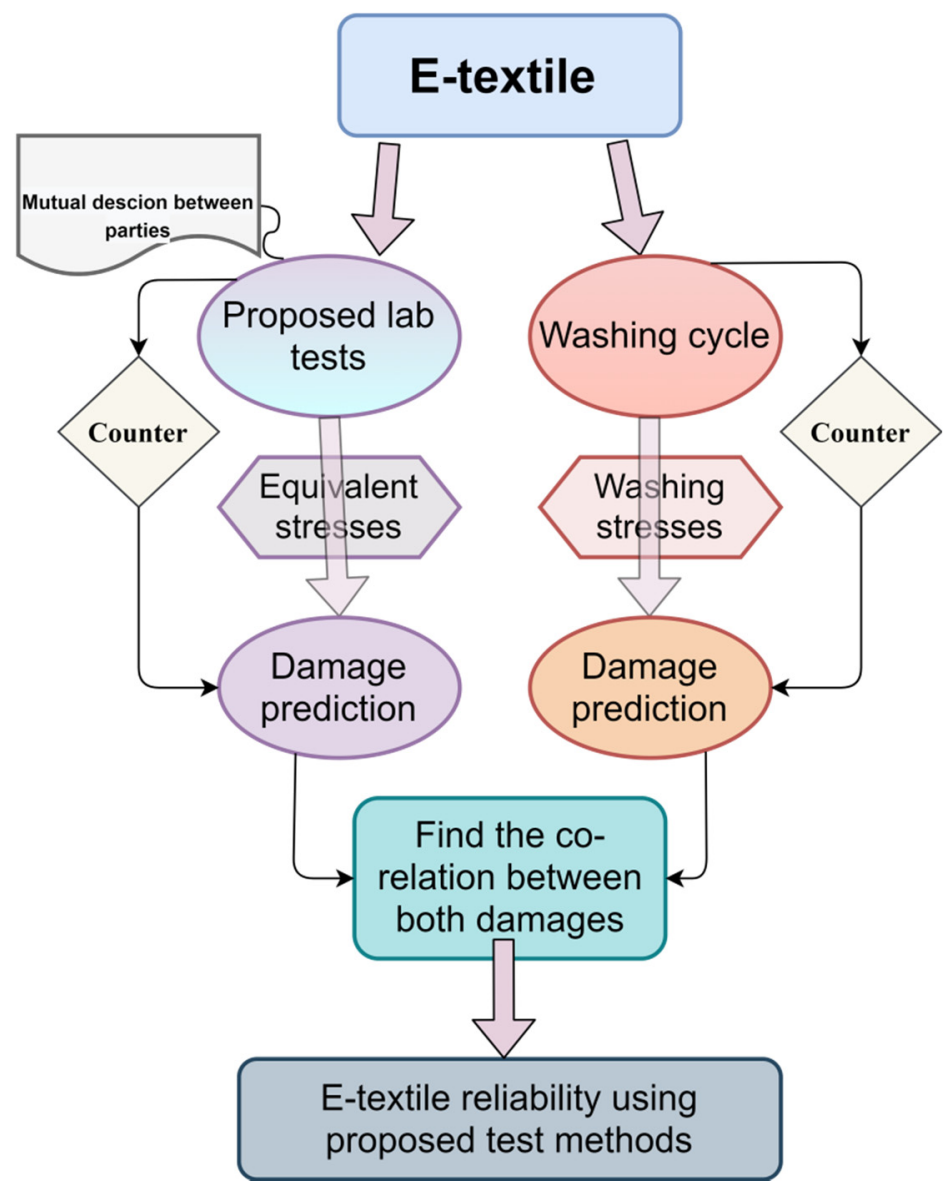

Figure 19. Proposed washing prediction protocol.

Several research groups are working on e-textile prototypes, and we can see many valuable products being designed for specific applications. However, there is no available standard of washability and reliability for e-textile products. This is why various groups 
used their locally available wash processes to claim washability. Some preferred ISO 6330 for washability claims, while others decided to follow ISO 105. Similarly, some groups used AATCC 6 for their products. Diverse research articles were found claiming the washability of products for a different number of wash cycles. Some used laboratory-based wash machines, and others preferred user-oriented wash processes.

Different organizations are in the process of developing reliability standards for etextile systems. Currently, some initial drafts for reliability standards are available on the market; however, detailed e-textile system norms are still not yet available on the market.

ASTM WK61480 [105] is a standard test draft related to the durability of textile electrodes after laundering. AATCC RA111 [106] explains electrically integrated textiles after home laundering. IEC 63,203 [107] is under process as a working draft for wearable electronic devices in the supervision of the sub-committee TC124 from the "International Electrotechnical Commission (IEC)." It is a series of documents covering different portions related to wearable e-textiles. Part 204-1 is a working draft that describes the washability and durability of leisure and sports-related wearable e-textile systems. Washing test conditions, pre-treatments, post washing treatments, and test result protocols are discussed. However, there is still no explanation related to different behavior for various e-textile components added in this draft. Part 101-1 covers the norms and terminologies related to wearable e-textile systems. Similarly, part 201-3 discusses textile-based electrically conductive tracks in terms of their linear electrical resistances and microclimate testing for fabric samples. Additionally, parts 401 and 402 explain device and system functionality evaluation tests for textile-based sensors, respectively.

A guideline for connection yarns in e-textile systems (IPC-8941) is being developed by IPC (Institute of Printed Circuits, www.ipc.org, accessed on 12 November 2021) under the D-71 committee, e-textiles joining and interconnection techniques sub-committee. This industry guideline will provide key considerations and best practices for connecting etextile components. These components can be attached to e-textiles to augment their performance. It will help users and manufacturers to work together to make the best decisions for selecting connector types, connection materials, and connection processes based on the e-textile technology to be used and the component to which the e-textile will be connected.

IPC 8921 [108], published in 2019, is another effort to develop the requirements for woven and knitted electronic textiles integrated with conductive fibers, yarns, and wires. This standard highlights the guidelines for the critical characteristics and durability of woven and knitted e-textiles integrated with conductive fibers, conductive yarns, and/or wires. It also explains the classifications for knitted and woven e-textiles and their definitions.

Another task group in IPC, D-73a (e-textiles printed electronics design standard task group), is working on e-textile printing electronic designs. This standard will establish specific requirements for the design of printed electronic applications, and the types of components mounting and interconnecting structures on coated or treated textile substrates. As pertains to this standard, the textile substrate could be a bare textile or an integrated e-textile (e.g., woven or knitted e-textile). Coated or treated textile substrates are textiles that have or will have a coating or treatment localized in one spot or across the full substrate. The target standard draft will be finalized in late 2021 under the standard norm IPC- 8952.

Currently, a group under the umbrella of IPC is working on the new e-textile classifications and standards sub-committee (D-75a-EU) dedicated to the companies producing electronic circuits and components to be involved in e-textile product development and manufacturing. This protocol will establish the required testing and reliability expectations for wearable e-textile systems. A wearable e-textile will be any wearable product that is a complete system utilizing non-electrical textiles and e-textiles (woven, knitted, printed, etc.) with attached/connected functional components, sensors, devices, etc. This working group's initial target is to define wearable e-textile and other e-textile structures that could be part of this system (e.g., wires on a textile, laminated, conductive polymers, sensors, actuators, etc.). Not all smart medical healthcare systems fall under medical rules and 
regulations. The durability of the material used for sensitive medical treatments is also a point of concern for medical experts. Similarly, security issues regarding the breach of sensitive patient data are also another point of concern in healthcare e-textile devices.

\section{Conclusions}

The area of healthcare and medical treatment devices is rapidly growing and increasingly includes textile structures as substrates or even active systems. Several issues still have to be addressed; amongst them, the reliability and washability of the e-textile systems is one of the most important. Currently, activities leading to the establishment of the wearable e-textile standards and testing methods are intensively driven. Several groups are working on a global level to help the electronics industry to better design and produce their components and devices to make them compatible with the soft, lightweight textile structures and their specific uses in the field of medical and healthcare systems. This review article aimed at a better understanding of the challenges and issues that must be taken into account and addressed by both textile and electronics companies to produce reliable and helpful e-textile medical devices and systems.

Author Contributions: X.T., C.C. and V.K. defined the general concept, and provided the guidelines for this study. S.u.Z. performed all procedures, reviewed the recent developments, and wrote the manuscript. All authors have read and agreed to the published version of the manuscript.

Funding: This research was funded by GEMTEX laboratory, France, and National Textile University, Pakistan.

Institutional Review Board Statement: The study was conducted according to the guidelines of the Declaration of Helsinki. Ethical review and approval were waived for this study as this study does not involve any humans or animals.

Informed Consent Statement: Informed consent was obtained from all subjects involved in the study.

Data Availability Statement: The data presented in this study are available on request from corresponding author.

Conflicts of Interest: The authors declare no conflict of interest.

\section{References}

1. Ankhili, A.; Tao, X.; Cochrane, C.; Coulon, D.; Koncar, V. Washable and Reliable Textile Electrodes Embedded into Underwear Fabric for Electrocardiography (ECG) Monitoring. Materials 2018, 11, 256. [CrossRef]

2. Wu, H.; Huang, Y.; Xu, F.; Duan, Y.; Yin, Z. Energy Harvesters for Wearable and Stretchable Electronics: From Flexibility to Stretchability. Adv. Mater. 2016, 28, 9881-9919. [CrossRef]

3. Waqar, S.; Wang, L.; John, S. Piezoelectric Energy Harvesting from Intelligent Textiles. In Electronic Textiles; Elsevier: Amsterdam, The Netherlands, 2015; pp. 173-197, ISBN 978-0-08-100201-8.

4. Bahru, R.; Hamzah, A.A.; Mohamed, M.A. Thermal Management of Wearable and Implantable Electronic Healthcare Devices: Perspective and Measurement Approach. Int. J. Energy Res. 2020, 45, 1517-1534. [CrossRef]

5. Hussain, M.M.; El-Atab, N. Handbook of Flexible and Stretchable Electronics; CRC Press: Boca Raton, FL, USA, 2019.

6. Wang, L.; Fu, X.; He, J.; Shi, X.; Chen, T.; Chen, P.; Wang, B.; Peng, H. Application Challenges in Fiber and Textile Electronics. Adv. Mater. 2020, 32, 1901971. [CrossRef] [PubMed]

7. Mecnika, V.; Scheulen, K.; Anderson, C.F.; Hörr, M.; Breckenfelder, C. Joining Technologies for Electronic Textiles. In Electronic Textiles; Elsevier: Amsterdam, The Netherlands, 2015; pp. 133-153, ISBN 978-0-08-100201-8.

8. uz Zaman, S.; Tao, X.; Cochrane, C.; Koncar, V. Understanding the Washing Damage to Textile ECG Dry Skin Electrodes, Embroidered and Fabric-Based; Set up of Equivalent Laboratory Tests. Sensors 2020, 20, 1272. [CrossRef] [PubMed]

9. Tseghai, G.B.; Malengier, B.; Fante, K.A.; Nigusse, A.B.; Langenhove, L.V. Integration of Conductive Materials with Textile Structures, an Overview. Sensors 2020, 20, 6910. [CrossRef] [PubMed]

10. Pang, Y.; Yang, Z.; Yang, Y.; Ren, T. Wearable Electronics Based on 2D Materials for Human Physiological Information Detection. Small 2020, 16, 1901124. [CrossRef]

11. Ismar, E.; Tao, X.; Rault, F.; Dassonville, F.; Cochrane, C. Towards Embroidered Circuit Board From Conductive Yarns for E-Textiles. IEEE Access 2020, 8, 9. [CrossRef]

12. Valentine, L.; Ballie, J.; Bletcher, J.; Robertson, S.; Stevenson, F. Design Thinking for Textiles: Let's Make It Meaningful. Design J. 2017, 20, S964-S976. [CrossRef] 
13. Scataglini, S.; Andreoni, G.; Gallant, J. A Review of Smart Clothing in Military. In Proceedings of the 2015 Workshop on Wearable Systems and Applications-WearSys '15, Florence, Italy, 18 May 2015; pp. 53-54.

14. Abed, A.; Cochrane, C.; Boussu, F.; Cherkaoui, O.; Elmoznine, R. Design and Development of a Piezo-Resistive Sensor Based on PEDOT: PSS Applied to Sisal's Natural Fiber for Monitoring of 3D Warp Interlock Fabric. IOP Conf. Ser. Mater. Sci. Eng. 2020, 827, 012019. [CrossRef]

15. Kim, G.; Vu, C.C.; Kim, J. Single-Layer Pressure Textile Sensors with Woven Conductive Yarn Circuit. Appl. Sci. 2020, 10, 2877. [CrossRef]

16. Park, S.; Jayaraman, S. Smart Textiles: Wearable Electronic Systems. MRS Bull. 2003, 28, 585-591. [CrossRef]

17. Park, S.; Jayaraman, S. Enhancing the Quality of Life through Wearable Technology. IEEE Eng. Med. Biol. Mag. 2003, 22, 41-48. [CrossRef]

18. Tao, X. Smart Technology for Textiles and Clothing-Introduction and Overview. In Smart Fibres, Fabrics and Clothing; Elsevier: Amsterdam, The Netherlands, 2001; pp. 1-6, ISBN 978-1-85573-546-0.

19. Koncar, V. Introduction to Smart Textiles and Their Applications. In Smart Textiles and Their Applications; Elsevier: Amsterdam, The Netherlands, 2016; pp. 1-8, ISBN 978-0-08-100574-3.

20. Koncar, V. Smart Textiles for Monitoring and Measurement Applications. In Smart Textiles for In Situ Monitoring of Composites; Elsevier: Amsterdam, The Netherlands, 2019; pp. 1-151, ISBN 978-0-08-102308-2.

21. Stoppa, M.; Chiolerio, A. Wearable Electronics and Smart Textiles: A Critical Review. Sensors 2014, 14, 11957-11992. [CrossRef]

22. Rambausek, L. Textronics-Definition, Development and Characterization of Fibrous Organic Field Effect Transistors. Ph.D. Thesis, Ghent University, Ghent, Belhium, 2014.

23. Simegnaw, A.A.; Malengier, B.; Rotich, G.; Tadesse, M.G.; Van Langenhove, L. Review on the Integration of Microelectronics for E-Textile. Materials 2021, 14, 5113. [CrossRef]

24. de Mulatier, S.; Nasreldin, M.; Delattre, R.; Ramuz, M.; Djenizian, T. Electronic Circuits Integration in Textiles for Data Processing in Wearable Technologies. Adv. Mater. Technol. 2018, 3, 1700320. [CrossRef]

25. ISO ISO/TR 23383. 2020. Available online: https://www.iso.org/cms/render/live/fr/sites/isoorg/contents/data/standard/07 /53/75383.html (accessed on 15 March 2021).

26. Nayak, R.; Wang, L.; Padhye, R. Electronic Textiles for Military Personnel. In Electronic Textiles; Elsevier: Amsterdam, The Netherlands, 2015; pp. 239-256, ISBN 978-0-08-100201-8.

27. Kuroda, T.; Takahashi, H.; Masuda, A. Chapter 9-Woven Electronic Textiles. In Wearable Sensors, 2nd ed.; Sazonov, E., Ed.; Academic Press: Oxford, UK, 2021; pp. 249-275, ISBN 978-0-12-819246-7.

28. Fleury, A.; Sugar, M.; Chau, T. E-Textiles in Clinical Rehabilitation: A Scoping Review. Electronics 2015, 4, 173-203. [CrossRef]

29. Teferra, M.N.; Kourbelis, C.; Newman, P.; Ramos, J.S.; Hobbs, D.; Clark, R.A.; Reynolds, K.J. Electronic Textile Electrocardiogram Monitoring in Cardiac Patients: A Scoping Review Protocol. JBI Database Syst. Rev. Implement. Rep. 2019, 17, 147-156. [CrossRef] [PubMed]

30. Smart Textiles and Their Applications-1st Edition. Available online: https://www.elsevier.com/books/smart-textiles-andtheir-applications/koncar/978-0-08-100574-3 (accessed on 27 August 2021).

31. Gopalsamy, C.; Park, S.; Rajamanickam, R.; Jayaraman, S. The wearable motherboard TM: The first generation of adaptive and responsive textile structures (ARTS) for medical applications. Virtual Real. 2005, 4, 152-168.

32. Shah, A.; Ahirrao, S.; Phansalkar, S.; Kotecha, K. Survey on: Applications of Smart Wearable Technology in Health Insurance. IOP Conf. Ser. Mater. Sci. Eng. 2021, 1042, 012025. [CrossRef]

33. Tao, X.; Huang, T.-H.; Shen, C.-L.; Ko, Y.-C.; Jou, G.-T.; Koncar, V. Bluetooth Low Energy-Based Washable Wearable Activity Motion and Electrocardiogram Textronic Monitoring and Communicating System. Adv. Mater. Technol. 2018, 3, 1700309. [CrossRef]

34. Kim, H.; Kang, T.-H.; Ahn, J.; Han, H.; Park, S.; Kim, S.J.; Park, M.-C.; Paik, S.; Hwang, D.K.; Yi, H.; et al. Spirally Wrapped Carbon Nanotube Microelectrodes for Fiber Optoelectronic Devices beyond Geometrical Limitations toward Smart Wearable E-Textile Applications. ACS Nano 2020, 14, 17213-17223. [CrossRef] [PubMed]

35. Wearable Healthcare Devices Market-Global Forecast to 2025/MarketsandMarkets. Available online: https://www. marketsandmarkets.com/Market-Reports / wearable-medical-device-market-81753973.html?_cf_chl_captcha_tk_=pmd_ cVzQgXHOplhxpc1dXJMJDiAr6z_kBujbP4vmF2_k0AU-1635425122-0-gqNtZGzNAzujcnBszQe9 (accessed on 31 October 2021).

36. Bystricky, T.; Moravcova, D.; Kaspar, P.; Soukup, R.; Hamacek, A. A Comparison of Embroidered and Woven Textile Electrodes for Continuous Measurement of ECG. In Proceedings of the 2016 39th International Spring Seminar on Electronics Technology (ISSE), Pilsen, Czech Republic, 18-22 May 2016; pp. 7-11.

37. Ankhili, A.; Tao, X.; Cochrane, C.; Koncar, V.; Coulon, D.; Tarlet, J.-M. Ambulatory Evaluation of ECG Signals Obtained Using Washable Textile-Based Electrodes Made with Chemically Modified PEDOT:PSS. Sensors 2019, 19, 416. [CrossRef] [PubMed]

38. Medical Smart Textile Market Scope and Challenges 2018-2027 by Players, Technology and Applications I MarketResrarchFuture. Com IMedgadget. Available online: https://www.medgadget.com/2018/08/medical-smart-textile-market-scope-andchallenges-2018-2027-by-players-technology-and-applications-marketresrarchfuture-com.html (accessed on 22 December 2020).

39. Scataglini, S.; Moorhead, A.P.; Feletti, F. A Systematic Review of Smart Clothing in Sports: Possible Applications to Extreme Sports. Muscle Ligaments Tendons J. 2020, 10, 333. [CrossRef]

40. Sport T-Shirt. Available online: https://emglare.com/products/sport-tshirt (accessed on 21 December 2020). 
41. Gao, Y.; Yu, L.; Yeo, J.C.; Lim, C.T. Flexible Hybrid Sensors for Health Monitoring: Materials and Mechanisms to Render Wearability. Adv. Mater. 2020, 32, 1902133. [CrossRef]

42. Pulse Oximeter Market I By Product, Type, Technology I Global Forecast to 2026 I MarketsandMarkets. Available online: https: //www.marketsandmarkets.com/Market-Reports/pulse-oximeter-market-68168578.html (accessed on 31 October 2021).

43. Hexoskin (Carré Technologies Inc.) Hexoskin Smart Shirts-Cardiac, Respiratory, Sleep \& Activity Metrics. Available online: https: / / www.hexoskin.com/ (accessed on 16 November 2021).

44. Huang, C.-T.; Shen, C.-L.; Tang, C.-F.; Chang, S.-H. A Wearable Yarn-Based Piezo-Resistive Sensor. Sens. Actuators A Phys. 2008, 141, 396-403. [CrossRef]

45. Gao, W.; Emaminejad, S.; Nyein, H.Y.Y.; Challa, S.; Chen, K.; Peck, A.; Fahad, H.M.; Ota, H.; Shiraki, H.; Kiriya, D.; et al. Fully Integrated Wearable Sensor Arrays for Multiplexed in Situ Perspiration Analysis. Nature 2016, 529, 509-514. [CrossRef]

46. Gaubert, V.; Gidik, H.; Koncar, V. Boxer Underwear Incorporating Textile Moisture Sensor to Prevent Nocturnal Enuresis. Sensors 2020, 20, 3546. [CrossRef]

47. Rymarczyk, T.; Vejar, A.; Nita, P.; Stefaniak, B.; Wos, M.; Oleszek, M. Using Electrical Tomography for Remote Monitoring Cardiopulmonary State of Patients by Complementary Investigation Techniques. In Proceedings of the 2019 19th International Symposium on Electromagnetic Fields in Mechatronics, Electrical and Electronic Engineering (ISEF), Nancy, France, 29-31 August 2019; pp. 1-2.

48. Mordon, S.; Cochrane, C.; Tylcz, J.B.; Betrouni, N.; Mortier, L.; Koncar, V. Light Emitting Fabric Technologies for Photodynamic Therapy. Photodiagn. Photodyn. Ther. 2015, 12,1-8. [CrossRef]

49. Gaubert, V.; Gidik, H.; Bodart, N.; Koncar, V. Quantification of the Silver Content of a Silver-Plated Nylon Electrode According to the Nature of the Laundering Detergent. IOP Conf. Ser. Mater. Sci. Eng. 2020, 827, 012033. [CrossRef]

50. Quandt, B.M.; Scherer, L.J.; Boesel, L.F.; Wolf, M.; Bona, G.-L.; Rossi, R.M. Body-Monitoring and Health Supervision by Means of Optical Fiber-Based Sensing Systems in Medical Textiles. Adv. Healthc. Mater. 2015, 4, 330-355. [CrossRef]

51. Grancarić, A.M.; Jerković, I.; Koncar, V.; Cochrane, C.; Kelly, F.M.; Soulat, D.; Legrand, X. Conductive Polymers for Smart Textile Applications. J. Ind. Text. 2018, 48, 612-642. [CrossRef]

52. NeoMedLight Bilicocoon®. Available online: https://www.neomedlight.com/bilicocoon/ (accessed on 22 December 2020).

53. Parvin, F.; Islam, S.; Urmy, Z.; Ahmed, S. A study on the textile materials applied in human medical treatment. J. Physiother. Rehabil. Stud. 2020, 1, 2566. [CrossRef]

54. Baldoli, I.; Mazzocchi, T.; Paoletti, C.; Ricotti, L.; Salvo, P.; Dini, V.; Laschi, C.; Francesco, F.D.; Menciassi, A. Pressure Mapping with Textile Sensors for Compression Therapy Monitoring. Proc. Inst. Mech. Eng. H 2016, 230, 795-808. [CrossRef] [PubMed]

55. Andrew Cohen Heart-Monitoring T-Shirt. Available online: https://www.sporttechie.com/smart-textile-company-kymiracardiac-monitoring-tshirt-athletes/ (accessed on 15 March 2021).

56. Xiaomi Mijia Cardiogram T-Shirt: Smart T-Shirt with ECG Measurement. Xiaomi Planet. 2020. Available online: https: / / xiaomiplanets.com/Xiaomi-mijia-cardiogram-t-shirt-1/ (accessed on 12 February 2021).

57. Daniely, H. A T-Shirt That Monitors Your Heart. HealthWatch Ltd.IHealthcare Wearables. 2017. Available online: https: / / healthwatchtech.com/a-t-shirt-that-monitors-your-heart/ (accessed on 16 March 2021).

58. BioMan + Products \& Services. AiQ Smart Clothing. Available online: https://www.aiqsmartclothing.com/product-service/ bioman-plus/\#tab-id-3 (accessed on 12 February 2021).

59. T-Shirt Short Sleeve + HRM. Available online: https://store.sensoriafitness.com/t-shirt-short-sleeve-hrm/ (accessed on 21 December 2020).

60. The Next Phase for Medical Wearables-Verdict Medical Devices. Available online: https://medical-technology.nridigital.com/ medical_technology_jun21/next_phase_medical_wearables (accessed on 31 October 2021).

61. Nag, A.; Mukhopadhyay, S.C.; Kosel, J. Wearable Flexible Sensors: A Review. IEEE Sens. J. 2017, 17, 3949-3960. [CrossRef]

62. Bosowski, P.; Hoerr, M.; Mecnika, V.; Gries, T.; Jockenhövel, S. Design and Manufacture of Textile-Based Sensors. In Electronic Textiles; Elsevier: Amsterdam, The Netherlands, 2015; pp. 75-107, ISBN 978-0-08-100201-8.

63. Trung, T.Q.; Lee, N.-E. Flexible and Stretchable Physical Sensor Integrated Platforms for Wearable Human-Activity Monitoringand Personal Healthcare. Adv. Mater. 2016, 28, 4338-4372. [CrossRef]

64. van den Brand, J.; de Kok, M.; Koetse, M.; Cauwe, M.; Verplancke, R.; Bossuyt, F.; Jablonski, M.; Vanfleteren, J. Flexible and Stretchable Electronics for Wearable Health Devices. Solid-State Electron. 2015, 113, 116-120. [CrossRef]

65. Fukuma, N.; Hasumi, E.; Fujiu, K.; Waki, K.; Toyooka, T.; Komuro, I.; Ohe, K. Feasibility of a T-Shirt-Type Wearable Electrocardiography Monitor for Detection of Covert Atrial Fibrillation in Young Healthy Adults. Sci. Rep. 2019, 9, 11768. [CrossRef] [PubMed]

66. Hong, Y.J.; Jeong, H.; Cho, K.W.; Lu, N.; Kim, D. Wearable and Implantable Devices for Cardiovascular Healthcare: From Monitoring to Therapy Based on Flexible and Stretchable Electronics. Adv. Funct. Mater. 2019, 29, 1808247. [CrossRef]

67. Meghrazi, M.A.; Tian, Y.; Mahnam, A.; Bhattachan, P.; Eskandarian, L.; Kakhki, S.T.; Popovic, M.R. Multichannel ECG Recording from Waist Using Textile Sensors. Biomed. Eng. Online 2020, 19, 48. [CrossRef] [PubMed]

68. Heo, J.S.; Hossain, M.F.; Kim, I. Challenges in Design and Fabrication of Flexible/Stretchable Carbon- and Textile-Based Wearable Sensors for Health Monitoring: A Critical Review. Sensors 2020, 20, 3927. [CrossRef]

69. Arquilla, K.; Webb, A.; Anderson, A. Textile Electrocardiogram (ECG) Electrodes for Wearable Health Monitoring. Sensors 2020, 20, 1013. [CrossRef] 
70. Wang, J.; Soltanian, S.; Servati, P.; Ko, F.; Weng, M. A Knitted Wearable Flexible Sensor for Monitoring Breathing Condition. J. Eng. Fibers Fabr. 2020, 15, 155892502093035. [CrossRef]

71. Shathi, M.A.; Chen, M.; Khoso, N.A.; Rahman, M.T.; Bhattacharjee, B. Graphene Coated Textile Based Highly Flexible and Washable Sports Bra for Human Health Monitoring. Mater. Des. 2020, 193, 108792. [CrossRef]

72. Saleh, S.M.; Jusob, S.M.; Harun, F.K.C.; Yuliati, L.; Wicaksono, D.H.B. Optimization of Reduced GO-Based Cotton Electrodes for Wearable Electrocardiography. IEEE Sensors J. 2020, 20, 7774-7782. [CrossRef]

73. Fu, Y.; Zhao, J.; Dong, Y.; Wang, X. Dry Electrodes for Human Bioelectrical Signal Monitoring. Sensors 2020, 20, 3651. [CrossRef]

74. Nigusse, A.B.; Malengier, B.; Mengistie, D.A.; Tseghai, G.B.; Van Langenhove, L. Development of Washable Silver Printed Textile Electrodes for Long-Term ECG Monitoring. Sensors 2020, 20, 6233. [CrossRef]

75. Kim, S.; Lee, S.; Jeong, W. EMG Measurement with Textile-Based Electrodes in Different Electrode Sizes and Clothing Pressures for Smart Clothing Design Optimization. Polymers 2020, 12, 2406. [CrossRef] [PubMed]

76. Shi, J.; Liu, S.; Zhang, L.; Yang, B.; Shu, L.; Yang, Y.; Ren, M.; Wang, Y.; Chen, J.; Chen, W.; et al. Smart Textile-Integrated Microelectronic Systems for Wearable Applications. Adv. Mater. 2020, 32, 1901958. [CrossRef] [PubMed]

77. Atakan, R.; Acikgoz Tufan, H.; Baskan, H.; Eryuruk, S.H.; Akalin, N.; Kose, H.; Li, Y.; Kursun Bahadir, S.; Kalaoglu, F. Design of an Electronic Chest-Band. IOP Conf. Ser. Mater. Sci. Eng. 2017, 254, 072002. [CrossRef]

78. Cao, R.; Pu, X.; Du, X.; Yang, W.; Wang, J.; Guo, H.; Zhao, S.; Yuan, Z.; Zhang, C.; Li, C.; et al. Screen-Printed Washable Electronic Textiles as Self-Powered Touch/Gesture Tribo-Sensors for Intelligent Human-Machine Interaction. ACS Nano 2018, 12, 5190-5196. [CrossRef] [PubMed]

79. Sliz, R.; Huttunen, O.-H.; Jansson, E.; Kemppainen, J.; Schroderus, J.; Kurkinen, M.; Fabritius, T. Reliability of R2R-Printed, Flexible Electrodes for e-Clothing Applications. Npj Flex. Electron. 2020, 4, 12. [CrossRef]

80. Qureshi, Y.; Tarfaoui, M.; Lafdi, K.; Lafdi, K. A Flexible Strain Sensor Design Based on Ny-6 Yarn Coated with Ag Nanoparticles for Real Time Strain Monitoring Application. Int. J. Mech. Prod. Eng. 2019, 7, 18-21.

81. Zhao, X.; Hua, Q.; Yu, R.; Zhang, Y.; Pan, C. Flexible, Stretchable and Wearable Multifunctional Sensor Array as Artificial Electronic Skin for Static and Dynamic Strain Mapping. Adv. Electron. Mater. 2015, 1, 1500142. [CrossRef]

82. Zhang, X.; Zhong, Y. A Silver/Silver Chloride Woven Electrode with Convex Based on Electrical Impedance Tomography. J. Text. Inst. 2020, 112, 1067-1079. [CrossRef]

83. Jin, H.; Matsuhisa, N.; Lee, S.; Abbas, M.; Yokota, T.; Someya, T. Enhancing the Performance of Stretchable Conductors for E-Textiles by Controlled Ink Permeation. Adv. Mater. 2017, 29, 1605848. [CrossRef] [PubMed]

84. Logothetis, I.; Vatansever Bayramol, D.; Gil, I.; Dabnichki, P.; Pirogova, E. Evaluating Silver-Plated Nylon (Ag/PA66) e-Textiles for Bioelectrical Impedance Analysis (BIA) Application. Meas. Sci. Technol. 2020, 31, 075101. [CrossRef]

85. Edmison, J.; Jones, M.; Lockhart, T.; Martin, T. An e-textile system for motion analysis. Stud. Health Technol. Inform. 2010, 108, 292.

86. Afroj, S.; Tan, S.; Abdelkader, A.M.; Novoselov, K.S.; Karim, N. Highly Conductive, Scalable, and Machine Washable GrapheneBased E-Textiles for Multifunctional Wearable Electronic Applications. Adv. Funct. Mater. 2020, 30, 2000293. [CrossRef]

87. Daňová, R.; Olejnik, R.; Slobodian, P.; Matyas, J. The Piezoresistive Highly Elastic Sensor Based on Carbon Nanotubes for the Detection of Breath. Polymers 2020, 12, 713. [CrossRef] [PubMed]

88. Tang, Y.; Chang, R.; Zhang, L.; Yan, F.; Ma, H.; Bu, X. Electrode Humidification Design for Artifact Reduction in Capacitive ECG Measurements. Sensors 2020, 20, 3449. [CrossRef] [PubMed]

89. Gong, Z.; Xiang, Z.; OuYang, X.; Zhang, J.; Lau, N.; Zhou, J.; Chan, C.C. Wearable Fiber Optic Technology Based on Smart Textile: A Review. Materials 2019, 12, 3311. [CrossRef] [PubMed]

90. Cinquino, M.; Prontera, C.; Pugliese, M.; Giannuzzi, R.; Taurino, D.; Gigli, G.; Maiorano, V. Light-Emitting Textiles: Device Architectures, Working Principles, and Applications. Micromachines 2021, 12, 652. [CrossRef]

91. Shen, J.; Chui, C.; Tao, X. Luminous Fabric Devices for Wearable Low-Level Light Therapy. Biomed. Opt. Express 2013, 4, 2925. [CrossRef] [PubMed]

92. Mordon, S.; Thécua, E.; Ziane, L.; Lecomte, F.; Deleporte, P.; Baert, G.; Vignion-Dewalle, A. Light Emitting Fabrics for Photodynamic Therapy: Technology, Experimental and Clinical Applications. Transl. Biophotonics 2020, 2, e202000005. [CrossRef]

93. Wang, J.; Lee, S.; Yokota, T.; Jimbo, Y.; Wang, Y.; Nayeem, M.O.G.; Nishinaka, M.; Someya, T. Nanomesh Organic Electrochemical Transistor for Comfortable On-Skin Electrodes with Local Amplifying Function. ACS Appl. Electron. Mater. 2020, 2, 3601-3609. [CrossRef]

94. Shahariar, H.; Kim, I.; Bhakta, R.; Jur, J.S. Direct-Write Printing Process of Conductive Paste on Fiber Bulks for Wearable Textile Heaters. Smart Mater. Struct. 2020, 29, 085018. [CrossRef]

95. Quandt, B.M.; Pfister, M.S.; Lübben, J.F.; Spano, F.; Rossi, R.M.; Bona, G.-L.; Boesel, L.F. POF-Yarn Weaves: Controlling the Light out-Coupling of Wearable Phototherapy Devices. Biomed. Opt. Express 2017, 8, 4316. [CrossRef]

96. Ismar, E.; uz Zaman, S.; Tao, X.; Cochrane, C.; Koncar, V. Effect of Water and Chemical Stresses on the Silver Coated Polyamide Yarns. Fibers Polym. 2019, 20, 2604-2610. [CrossRef]

97. uz Zaman, S.; Tao, X.; Cochrane, C.; Koncar, V. Launderability of Conductive Polymer Yarns Used for Connections of E-Textile Modules: Mechanical Stresses. Fibers Polym. 2019, 20, 2355-2366. [CrossRef]

98. Rotzler, S.; Kallmayer, C.; Dils, C.; von Krshiwoblozki, M.; Bauer, U.; Schneider-Ramelow, M. Improving the Washability of Smart Textiles: Influence of Different Washing Conditions on Textile Integrated Conductor Tracks. J. Text. Inst. 2020, 111, $1766-1777$. [CrossRef] 
99. Kazani, I.; De Mey, G.; Klepacko, R.; Hertleer, C.; Guxho, G.; Van Langenhove, L.; Napieralski, A. Influence of Dry Cleaning on the Electrical Resistance of Screen Printed Conductors on Textiles. Autex Res. J. 2016, 16, 146-153. [CrossRef]

100. Kazani, I.; Declercq, F.; Scarpello, M.L.; Hertleer, C.; Rogier, H.; Vande Ginste, D.; De Mey, G.; Guxho, G.; Van Langenhove, L. Performance Study of Screen-Printed Textile Antennas after Repeated Washing. Autex Res. J. 2014, 14, 47-54. [CrossRef]

101. Hwang, B.; Lund, A.; Tian, Y.; Darabi, S.; Müller, C. Machine-Washable Conductive Silk Yarns with a Composite Coating of Ag Nanowires and PEDOT:PSS. ACS Appl. Mater. Interfaces 2020, 12, 27537-27544. [CrossRef]

102. Salavagione, H.J.; Shuttleworth, P.S.; Fernández-Blázquez, J.P.; Ellis, G.J.; Gómez-Fatou, M.A. Scalable Graphene-Based Nanocomposite Coatings for Flexible and Washable Conductive Textiles. Carbon 2020, 167, 495-503. [CrossRef]

103. Liang, A.; Stewart, R.; Freire, R.; Bryan-Kinns, N. Effect of Bonding and Washing on Electronic Textile Stretch Sensor Properties. In Adjunct Proceedings of the 2019 ACM International Joint Conference on Pervasive and Ubiquitous Computing and Proceedings of the 2019 ACM International Symposium on Wearable Computers; ACM Press: London, UK, 2019; pp. 121-124.

104. uz Zaman, S.; Tao, X.; Cochrane, C.; Koncar, V. E-Textile Systems Reliability Assessment-A Miniaturized Accelerometer Used to Investigate Damage during Their Washing. Sensors 2021, 21, 605. [CrossRef]

105. WK61480 New Test Method for Durability of Smart Garment Textile Electrodes after Laundering. Available online: https: //www.astm.org/DATABASE.CART/WORKITEMS/WK61480.htm (accessed on 21 December 2020).

106. RA111. Electronically Integrated Textiles Test Methods. AATCC. Available online: https://aatcc.org/aatcc-committees/ra111 -electronically-integrated-textiles-test-methods / (accessed on 12 November 2021).

107. IEC-TC 124 Dashboard > Projects: Work Programme, Publications, Maintenance Cycle, Project Files, TC/SC in Figures. Available online: https:/ / www.iec.ch/dyn/www /f?p=103:38:0::.:FSP_ORG_ID,FSP_APEX_PAGE,FSP_PROJECT_ID:20537,109,101883 (accessed on 5 January 2021).

108. IPC-8921: Requirements for Woven and Knitted Electronic Textiles (E-Textiles) Integrated with Conductive Fibers, Conductive Yarns and/or Wires. Available online: https:/ /shop.ipc.org/IPC-8921-English-D (accessed on 21 December 2020). 